$-m N^{2}$

NOV 191993

OSTI
UCRL-ID 112775

Reprinted from Engineering Research, Development, and Technology.

Thrust Area Report FY 92

UCRL 53868-92

\title{
Materials Science and Engineering
}

\author{
Donald R. Lesuer
}

March, 1993

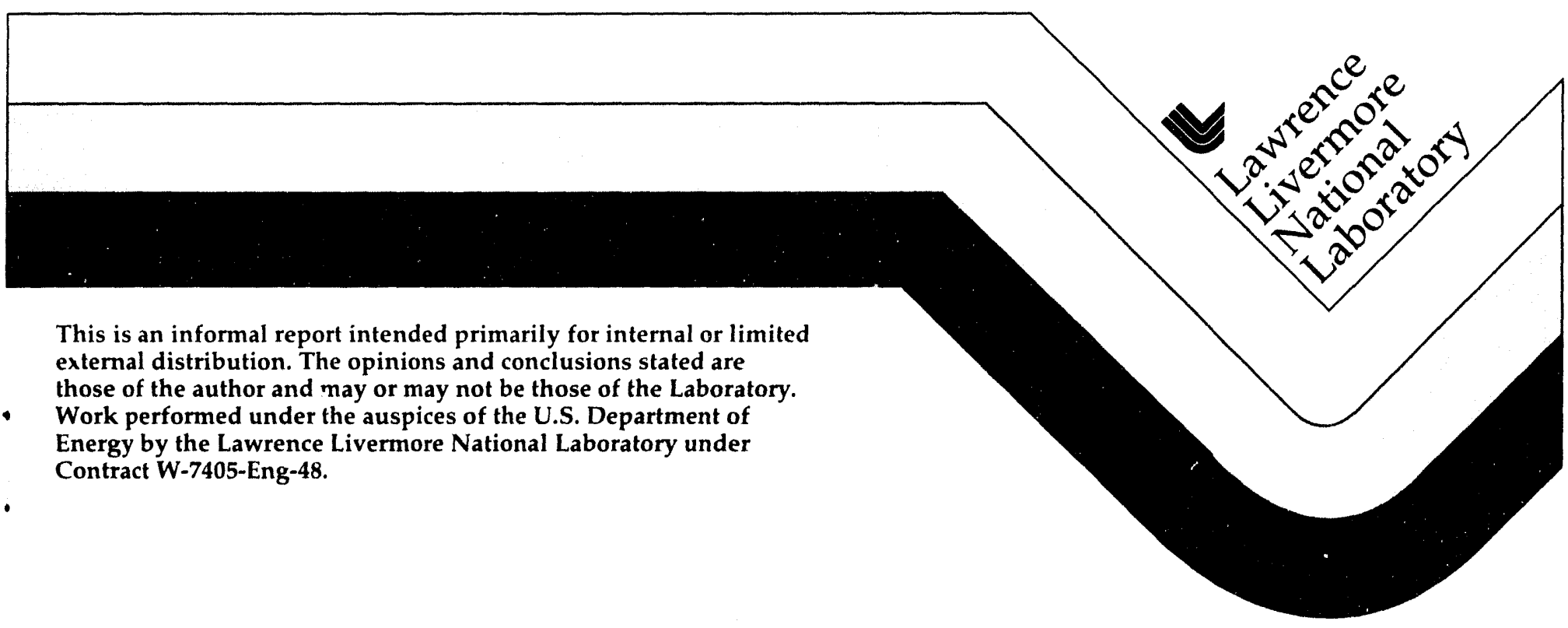


Disclaimer

This document was prepared as an account of work sponsored by an agency of the United States Government. Neither the United States Government nor the University of California nor any of their employees, makes any warranty, express or implied, or assumes any legal liability or responsibility for the accuracy, completeness, or usefulness of any information, apparatus, product, or process disclosed, or represents that its use would not infringe privately owned rights. Reference herein to any specific commercial products, process, or service by trade name, trademark, manufacturer, or otherwise, does not necessarily constitute or imply its endorsement, recommendation, or favoring by the United States Government or the University of California. The views and opinions of authors expressed herein do not necessarily state or reflect those of the United States Government or the University of California and shall not be used for advertising or product endorsement purposes.

This report has been reproduced directly from the best available copy.

Available to DOE and DOE contractors from the Office of Scientific and Technical Information P.O. Box 62, Oak Ridge, TN 37831

Prices available from (615) 576-8401, FTS 626-8401

Available to the public from the National Technical Information Service U.S. Department of Commerce 5285 Port Royal Rd. Springfield, VA 22161 


\title{
Materials Science and Engineering
}

\author{
Donald R. Lesuer
}

MASTER

rb 


\section{Materials Science and Engineering}

The objective of the Materials Science and Engineering thrust area is to enhance our understanding of the physical and mechanical behavior and the processing/structure/property correlations for structural materials that are of interest to Lawrence Livermore National Laboratory (LLNL) programs

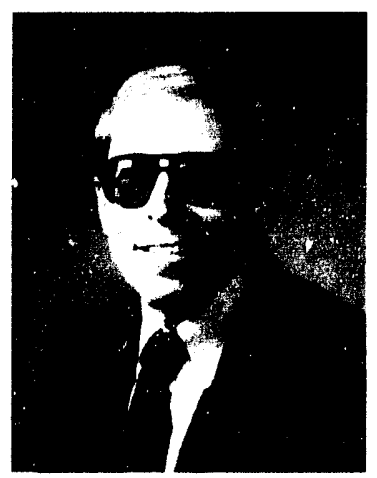
and U.S. industry. We also seek to enhance our ability to model the processing of these materials using LLNL's finite element codes. Our activities are currently focused on composite materials, superplasticity, and process modeling.

\section{Composite Materials}

Our work in composite materials is directed toward polymer matrix composites and metal matrix composites. LLNL has a long history of achievements in the investigation of polymer matrix composites. These materials have received considerable research attention and product application at LLNL and in industry because of their unique properties, including high specific strength, high specific stiffness, composition of low $Z$ atoms, corrosion resistrice, and the possibility for a low coefficient of thermal expansion. These properties can also be tailored to specific applications. During FY-92, we have focused on studying the three-dimensional mechanical response of continuous fiber, polymer matrix composites. These studies have significantly enhanced our understanding of the response of these materials and our ability to test and model this behavior using finite element codes. During FY-92 we have also studied the use of laser Raman spectroscopy to monitor in situ the state of cure in polymer matrix composites.

We also work on metal matrix composites (MMC's), which are materials of choice in applications requiring high specific strength and stiffness. These materials can have excellent thermal and electrical conductivity and, depending on the alloy matrix, excellent high-temperature behavior. During FY-92, we studied the processing/structure/property correlations in a unique form of MMC, called a laminated metal composite, in which alternating metallic layers are press-bonded together.

\section{Superplastic Materials}

Superplastic materials are crystalline solids that can be deformed in tension to such an extent that large strains will be attained at very low flow stresses. These materials, which deform like hot glass, permit components to be formed into shapes, the dimensions of which are very close to those desired in the final product ('net shape processing'). Thus, machining and machining-related operations can be reduced or eliminated. Our work in this technology has been stimulated by U.S. industry, which has demonstrated a strong interest in superplasticity for net shape processing. Currently, LLNL is engaged in two collaborative research and development projects with industry in the area of superplasticity. One project, with three partners, is developing the technology for commercial production of superplastic, ultra-highcarbon steels. Another project is developing a superplastic aluminum alloy with a faster forming rate and the capability for diffusion bonding. Su- 
perplastic forming can also reduce environmental, safety, and health problems in the Department of Energy nuclear weapons complex through the reduction of toxic and radioactive scrap produced during the fabrication of components. This year the thrust area has been studying the microstructural changes that take place during superpiastic deformation. A model is being developed for use in LLNL's finite element codes that will account for the influence of material microstructure and its evolution on the stress-strain-strain rate behavior of superplastic materials.

\section{Process Modeling}

Our work in process modeling is inspired by the enormous impact of this technology on economic manufacturing competitiveness and by the unique opportunities for LLNL to assist industry, given its extensive experience with modeling problems and its extensive computational resources and codes. Researchers within this thrust area are enhancing the capability of LLNL codes to model the casting process. Casting is a common industrial manufacturing process that is also very complex and influenced by many process and component variables. For these reasons, finite element modeling is a very powerful tool for understanding and predicting the success or failure of industrial casting operations. Work is continuing on a unique fluid-thermal-stress finite element code that will predict the final shape and stress state of precision cast parts.

\section{Section 6}

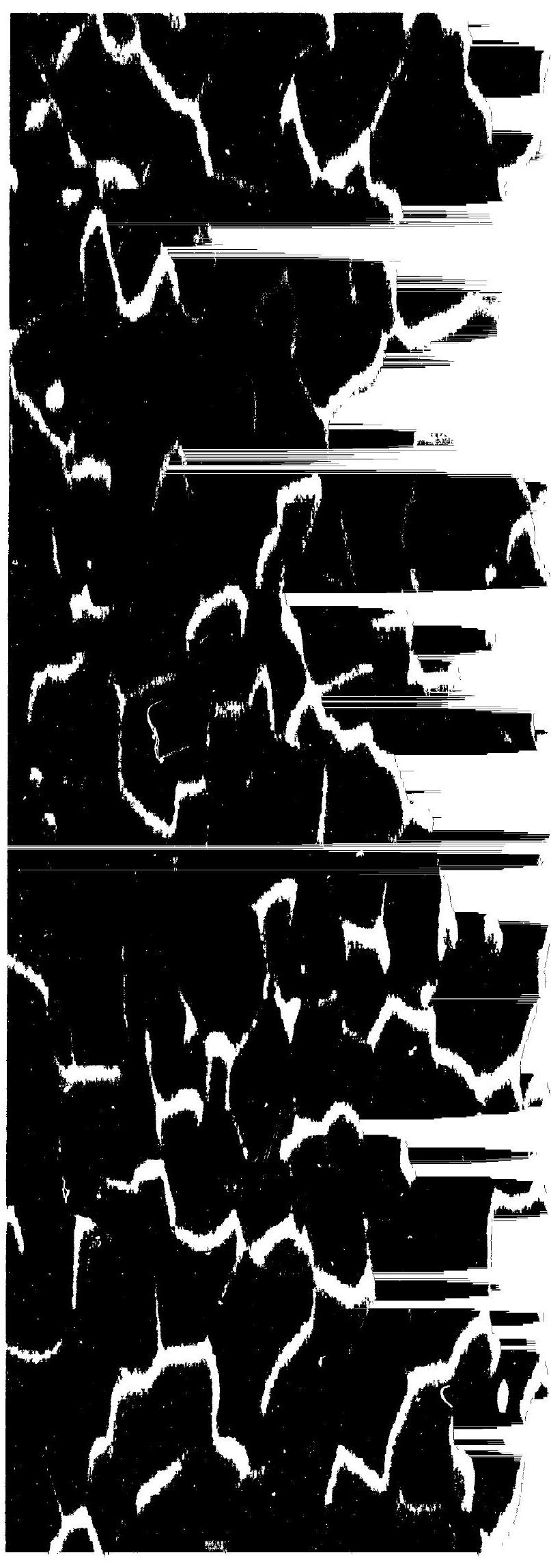

Donald R. Lesuer Thrust Aren Lender 


\section{Materials Science and Engineering}

Overview

Donald R. Lesuer, Thrust Area Leader

Processing and Characterization of Laminated Metal Composites

Chol K. Syn, Donald R. Lesuer, and O.D. Sherby

Casting Process Modeling

Arthur B. Shapiro

Characterizing the Failure of Composite Materials

Scott E. Groves, Roberto J. Sanchez, William W. Feng,

Albert E. Brown, Steven J. DeTeresa, and Richard E. Lyon

Fiber-Optic Raman Spectroscopy for Cure Monitoring of Advanced Polymer Composites

Richard E. Lyon, Thomas M. Vess, S. Michael Angel, and

M.L. Myrick

$6-17$

Modeling Superplastic Materials

Donald R. Lesuer, Chol K. Syn, Charles S. Preuss, and

Peter J. Raboin 


\section{Processing and Characterization of Laminated Metal Composites}

\author{
Chol K. Syn and Donald R. Lesuer \\ Engineering Sciences \\ Mechanical Enģineering
}

\author{
O.D. Sherby \\ Department of Materials Science \\ and Engineering \\ Stanfort Unizersity \\ Palo Alto, California
}

We have made laminated metal composites of (1) ultrahigh carbon steel $(1.8 \% \mathrm{C})$ and brass $(70 \% \mathrm{Cu}-30 \% \mathrm{Zn})$, and (2) $\mathrm{Al} 5182$ and $\mathrm{Al} 6061-25 \mathrm{vol} \% \mathrm{SiC}_{1}$. The laminates were prepared by hot pressing alternating layers of the component materials in an argon gas atmosphere. Tensile and fracture toughness were measured for different processing conditions of surface oxide descaling, layer thickness, and heat treatment. Descaling of the surface oxide prior to the pressbonding was found to eliminate premature delamination along interfaces, resulting in an increased yield strength and tensile ductility. Reduction in the layer thickness brought a large increase in tensile ductility, and a small decrease in yield strength and fracture toughness. T6 heat treatment on the Al laminates induced a substantial increase in the yield and tensile strength, but a decrease in tensile ductility. Fracture toughness measured both in the crackarrester and crack-divider orientations showed a large enhancement over that of the component materials. Damping capacity measurements also showed rather remarkable increases over that of the component materials.

\section{Introduction}

The idea of laminating different metals and alloys to form a composite material that exploits the good properties of the constituent materials has been known from antiquity: The' llind of $\mathrm{Hom}-$ er, e.g., describes Achilles' shield, made of two outer layers each of bronze and tin and one middle layer of gold. ${ }^{1}$ The idea has also been used in many industrial applications. ${ }^{2}$ However, most of the current industrial metal-based laminates contain only two or three layers, and are used to save material cost while maintaining required wear or corrosion resistance. Recent studies $3,4,5$ show that multilayer laminated metal composites (LMC's) can have superior damage-critical properties such as fracture toughness and fatigue resistance, over that of the component materials. Damage crack propagation in a laminate of dissimilar materials is inherently difficult, since an interface can act as a barrier to the crack propagation, especially when such an inter- face delaminates at the crack tip and blunts the crack." Studies, $3,4,5$ also show that it is possible to design a LMC with given performance character-

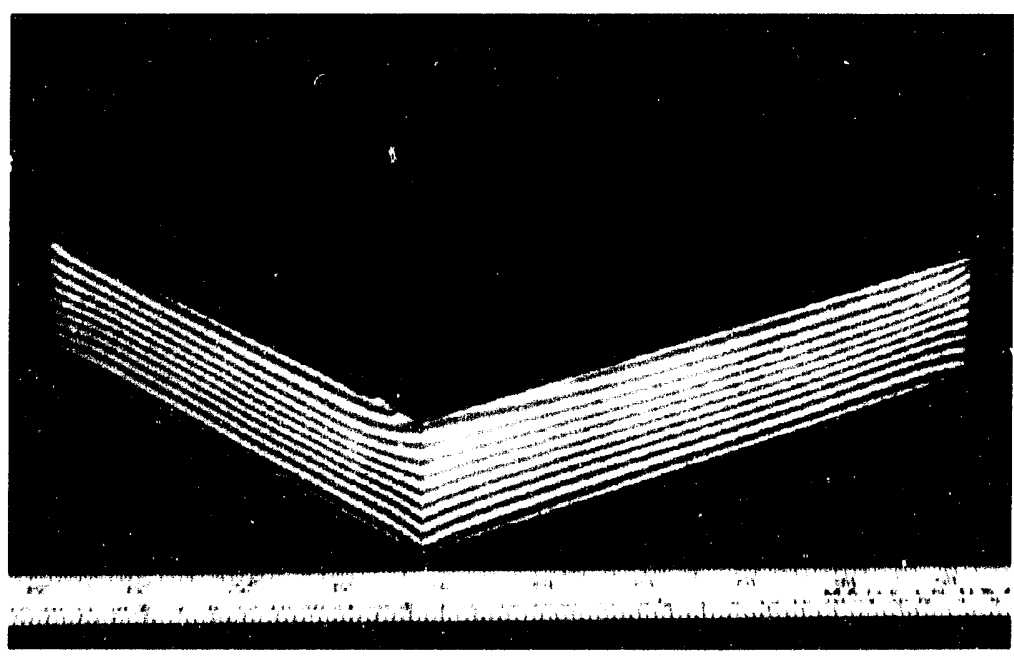

Fgure 1. An example of as pressed AI/ALSIC laminate after the edges were trimmed. 


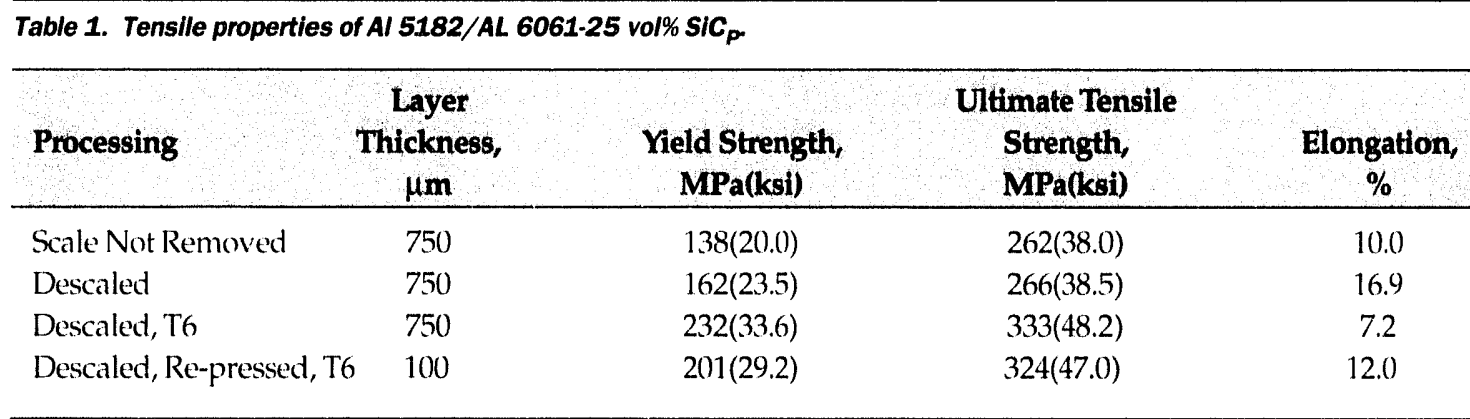

istics, through the choice of component materials, number of layers, thickness of the layers, and interfacial bond strength. A good example is the LMC formed by press-bonding alternate layers of ultrahigh carbon steel (UHCS) and mild steel. In this LMC, the dynamic fracture toughness is far higher

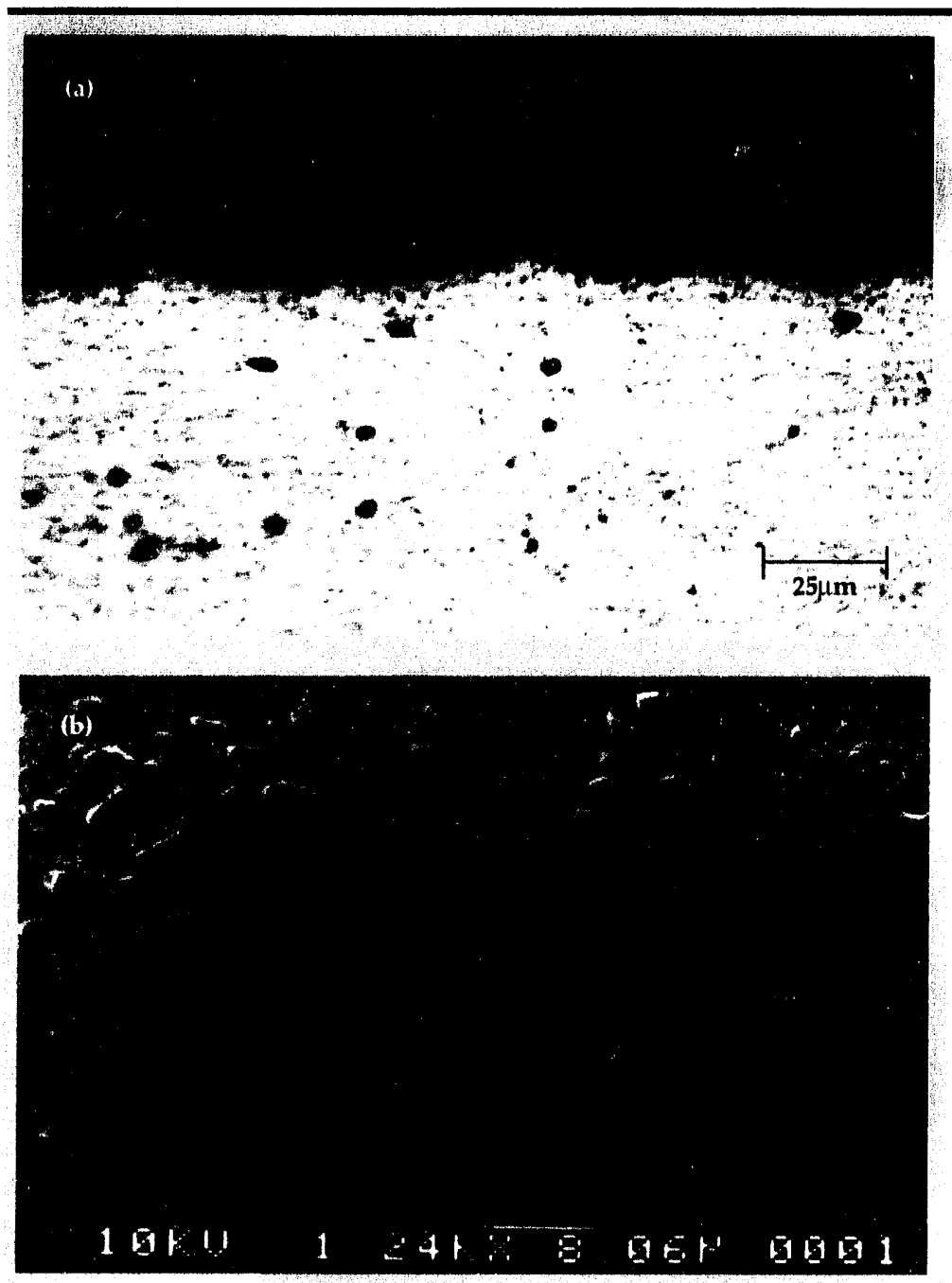

Figure 2. (a) Optical and (b) scanning electron microscope microstructure in the vicinity of an interface in Al/Al-SiC laminate. than that of either of the component materials. LMC's can also have damping capacity superior to that of the component materials, which can be very useful in structures requiring high acoustic damping.

\section{Progress}

We initiated the present research in FY-917 to investigate the influence of processing and structural variables on the mechanical properties of multilayer LMC's made of two constituent materials, one ductile but tough and the other brittle but strong. We chose in FY-91 to study two LMC systems, UHCS/brass and $\mathrm{Al} / \mathrm{Al}-\mathrm{SiC}_{\mathrm{P}}$, and continued this study in FY-92. These two systems were chosen to show that the toughness at ambient temperature of hard and brittle UHCS and $\mathrm{Al}-\mathrm{SiC}_{\Gamma}$ can be enhanced substantially by lamination with ductile but tough counterparts. The main thrust for FY-92 was to study the influence of the surface preparation of the component materials and the layer thickness of the laminates on their interfacial microstructure and mechanical properties.

\section{Experimental Procedure}

Materials and Processing. UHCS of a nominal composition of $\mathrm{Fe}-1.8 \% \mathrm{C}-1.65 \% \mathrm{Al}-1.5 \% \mathrm{Cr}-$ $0.5 \% \mathrm{Mn}$ was preprocessed $\mathrm{d}$ to have a fine-grained ferrite matrix of about $0.5-\mu \mathrm{m}$ grain size and spheroidized iron carbides on grain boundaries. Brass $(70 \%$ Cu-30\% Zn), Al 5182 (Al-4.5\% Mg$0.35 \% \mathrm{Mn}$ ), and $\mathrm{Al}-\mathrm{SiC}_{\mathrm{P}}$ [Al 6061 (Al-1.0\% Mg$0.6 \% \mathrm{Si}-0.28 \% \mathrm{Cu}-0.2 \% \mathrm{Cr}$ ) matrix with 25 vol. $\%$ $\mathrm{SiC}$ particulate] were obtained from commercial sources.

All materials were sliced to $50 \mathrm{~mm}-X-50 \mathrm{~mm}$ squares. $\mathrm{Al} 5182$ and $\mathrm{Al} 6061-\mathrm{SiC}_{\mathrm{P}}$, squares were descaled using an acid solution. UHCS and brass were surface-machined and degreased. A lami- 
nate containing an equal volume fraction of the two component materials was prepared by hotpressing a stack of alternate layers of the components. Each stack was pressed to one third or one fourth of its original height. Such a large reduction ensured good bonding at interfaces. UHCS laminates were press-bonded at $750^{\circ} \mathrm{C}$, and $\mathrm{Al}$ laminates at $450^{\circ} \mathrm{C}$. Some laminates were sliced into four equal-sized pieces, re-stacked, and re-pressed to obtain laminates with reduced layer thickness. Average layer thickness was about $750 \mu \mathrm{m}$ for both laminates after initial pressing; about $200 \mu \mathrm{m}$ for UHCS and $100 \mu \mathrm{m}$ for Al laminates after repressing. Some Al laminates were given the T6 heat treatment for the $\mathrm{Al} 6061$ matrix of the $\mathrm{Al}-\mathrm{SiC}_{\mathrm{P}}$, component.

Testing. Tensile tests were performed with flat specimens cut with the tensile axis parallel to the layers. Fracture toughness was measured with chevron-notched short bar or three-point bend bar specimens in which the notch was cut either in the crack arrester or crack divider orientation. In the crack arrester orientation, the crack front propagates in the thickness direction, cutting the layers sequentially. In the crack divider orientation, the crack front propagates through the laminate, cutting all the layers simultaneously. Damping capacity along the thickness direction of the laminates was evaluated by a pulse-echo method for the ultrasonic frequency range, and by a torsion bar technique for the 0.1 to $100 \mathrm{~Hz}$ range.

\section{Experimental Results}

Interfacial Bonding and Microstructure. The Al laminates that were chemically descaled and the UHCS laminates whose layers were surfacemachined prior to the press-bonding were well bonded and did not show any sign of interfacial delamination during machining of test specimens. A typical well-bonded as-pressed Al laminate, after its edges were trimmed, is shown in Fig. 1. Figure 2 shows an interface in the Al laminate shown in Fig. 1, both in (a) optical and (b) scanning electron microscope photomicrographs. No interfacial pores or unbonded areas, and no secondary phases are visible, indicating that no reaction between the component materials occurred.

Tensile Properties. Tensile properties of UHCS laminates were included in our FY-91 report. ${ }^{7}$ Summarized in Table 1 and Fig. 3 are the tensile properties for the Al laminates in the as-pressed, and T6 heat-treated conditions. For the T6 heat-treated condition, laminates with two different average layer thicknesses $(750 \mu \mathrm{m}$ and $100 \mu \mathrm{m})$ are com-

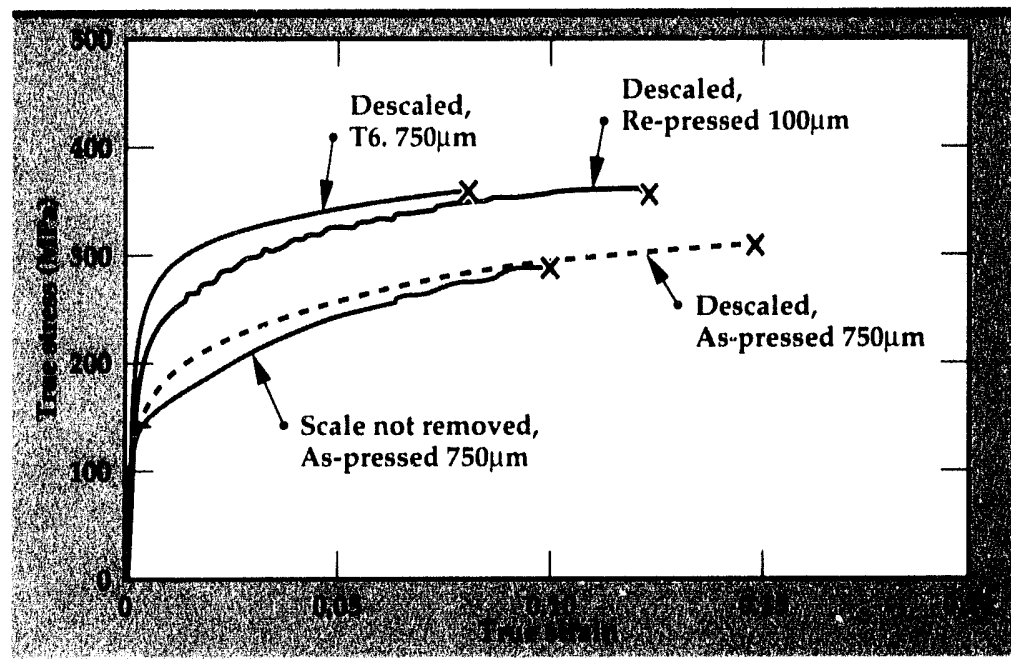

pared: the $750-\mu \mathrm{m}$-layer thickness material was obtained from the initial pressings, and the $100-\mu \mathrm{m}$ layer thickness material was obtained from repressings as described earlier.

Table 1 clearly shows the effect of surface oxide removal for two $750-\mu \mathrm{m}$-layer laminates. Descaling of the constituent materials led to a noticeable increase in the yield strength, from $138 \mathrm{MPa}(20 \mathrm{ksi})$ to $162 \mathrm{MPa}(23.5 \mathrm{ksi})$, and to a very substantial increase in ductility (by almost 7\%), from $10 \%$ to $16.9 \%$. No significant change in the ultimate tensile strength was observed. Figure 3 shows that the descaling treatment increases the flow stress over the entire strain range, most likely as a result of good bonding between the constituent layers, which prevents premature delamination. The importance of preventing delamination can probably be traced to the fact that in these materials, flow localization precedes fracture. Good bonding inhibits flow localization in the less ductile layers, which in turn results in greater elongation (and higher strength) before fracture.

Heat treatment considerably influences the mechanical properties, as shown by the results in Table 1 for $750 \mu \mathrm{m}$-layer laminates. The T6 treatment increased the yield and ultimate tensile strength by about $70 \mathrm{MPa}(10 \mathrm{ksi})$, but reduced the total elongation drastically, from about $17 \%$ to $7 \%$. Figure 3 shows that the flow stress was also increased.

Reduction of the layer thickness affects the tensile properties significantly. When the layer thickness was reduced from $750 \mu \mathrm{m}$ to about $100 \mu \mathrm{m}$ under the T6 heat-treated condition, the yield strength was decreased slightly, but the total elongation was increased rather remarkably, from $7.2 \%$ to $12 \%$. No significant change in the ultimate tensile strength was observed. A similar strong corre-
Figure 3. Tenslle stross-strain behavlor of AI/ALSIC lam Inato. Results shows the Influence of sur. face descalling, heat treatment, and layer thickness. 


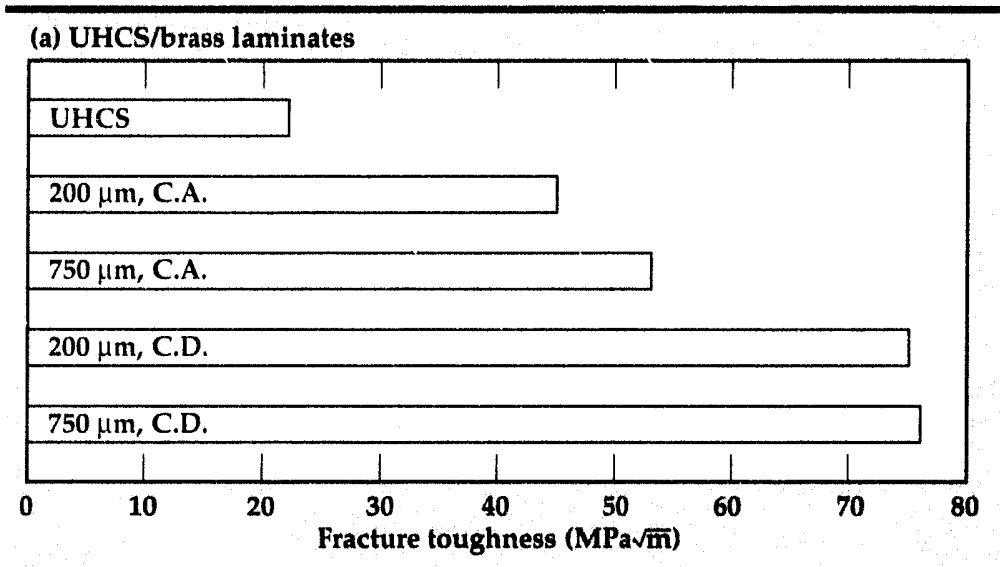

(b) Al 5182/Al 6061-SIC laminates

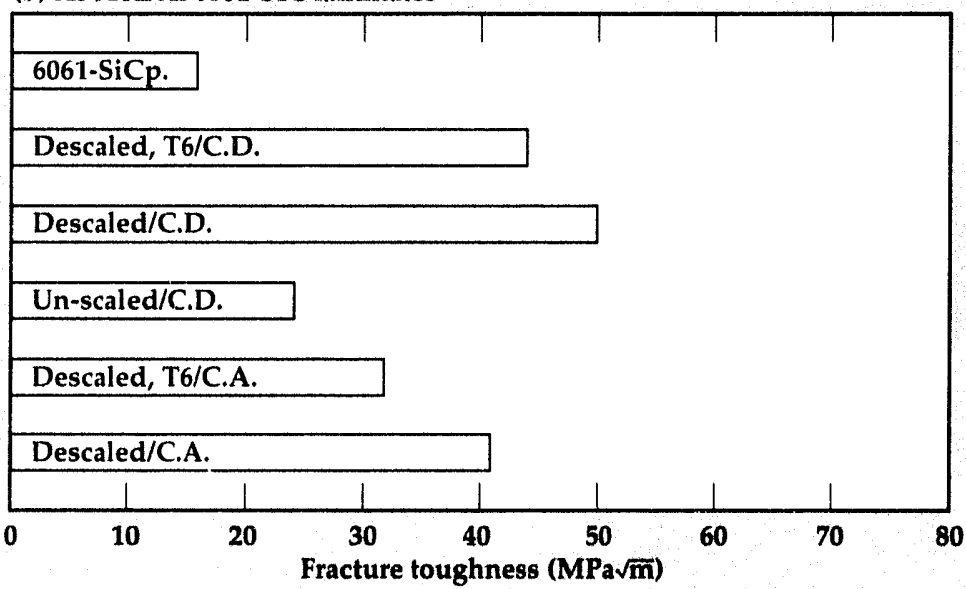

(c)

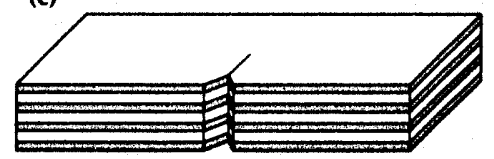

Crack divider (C.D.) orientation

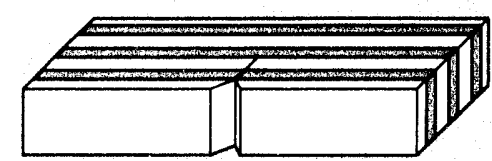

Crack arrester (C.A.) orientation

Figure 4. Fracture toughness measured (a) for the different layer thicknesses in UHCS/brass laminates and (b) for different processing conditions in Al/Al-SIC laminates. The inset drawings (c) define the crack divider (C.D.) and crack arrester (C.A.) orientations used in the fracture toughness tests.

lation between the layer thickness and ductility has been observed in the UHCS laminates, as reported in FY-91.7

Fracture Toughness. Results of fracture toughness tests are summarized in Fig. 4 for both UHCS and Al laminates. For laminates of both systems, it is clearly demonstrated in Fig. 4 that the lamination of a hard material (UHCS or Al $6061-\mathrm{SiC}_{1}$ ) with a ductile material (brass or Al 5182) results in substantial enhancement of toughness.

For UHCS/brass, the laminates with thin $(200 \mu \mathrm{m})$ layers show slightly lower toughness than the laminates with thick $(75) \mu \mathrm{m})$ layers regardless of the specimen orientation, i.e., crack arrester or crack divider, relative to the layers. This trend could be due to the influence of the interfacial delamination on crack grow th. Studies have shown that the delamina- tion tendency decreases with decreasing layer thickness. "Thus, it is likely that the higher toughness in the thick-layer laminates could be due to the blunting of an advancing crack by delamination. It is interesting to note, however, that delamination reduces the tensile ductility and strength, as observed for the tensile properties.

Interfacial delamination was observed also in the $\mathrm{Al}$ laminates regardless of the descaling or T6 treatment. The descaling treatment, however, led to an increased fracture toughness (measured in the crack divider orientation), as shown in Fig. 4, while the T6 treatment led to a reduced toughness (as measured both in the crack arrester and divider orientations). The beneficial effect of the descaling treatment results from the controlled and timely delamination of an interface as a crack approaches the interface. In the laminates made without the descaling treatment, delamination was extensive and occurred rather prematurely. The increased yield strength and reduced tensile ductility upon T6 treatment, as shown in Fig. 3, were reflected in the reduced fracture toughness, a trend observed similarly in most monolithic materials.

Damping Capacity. Damping capacity was measured only in the as-pressed condition, where the layer thickness was $750 \mu \mathrm{m}$ for both UHCS/ brass and Al laminates. At low frequencies, damping in the UHCS/brass laminate was two to three times the damping typically observed in brass or steel, and was lowest at $2 \mathrm{~Hz}$. Ultrasonic attenuation measurements of longitudinal waves showed that at $2.25 \mathrm{MHz}$, the UHCS/brass laminate had an attenuation coefficient of $160 \mathrm{~dB} / \mathrm{m}$, over 12 times the attenuation coefficient for the steel component and over four times the attenuation coefficient of the brass component. (1) The ultrasonic attenuation coefficient for the $\mathrm{Al} / \mathrm{Al}-\mathrm{SiC}_{\mathrm{l}}$, laminate $(266 \mathrm{~dB} / \mathrm{m})$ was greater than that for the UHCS/brass laminate. These results clearly show that $L M C$ 's can be more effective damping materials than their components.

\section{Future Work}

We are continuing to characterize the UHCS/ brass and $\mathrm{Al} / \mathrm{Al}-\mathrm{SiC}$ laminates regarding their (1) damping capacity in the audible frequency range, (2) fatigue behavior, (3) response to ballistic impact, and (4) deformation behavior at elevated temperature. We are planning to make LMC's of other light materials such as Mg alloys, (a) containing a high damping capacity material as a component and (b) containing an intermetallic or superalloy as a component. These new lami- 
nates will be tested for their strength, ductility, toughness, and other characteristics reported here for the UHCS/brass and Al laminates.

\section{Aclonowlodgements}

We sincerely appreciate assistance provided by Chris Steffani for descaling Al alloys; Ralph Otto and Bill Stutler for pressing laminates; Dick Sites for preparing test samples; Al Shields for conducting mechanical property tests; and Jim Ferreira for metallography.

1. The Ilind of Homer, translated by R. Lattimore, University of Chicago Press (Chicago, Illinois), 411 (lines 270-272), 1951

2. E.S. Wright and A.P. Levitt, "Laminated Metal Composites," Metallic Matrix Composite's, K.G. Kreider (Ed.), Academic Press (New York, New York), 37, 1974

3. C.K. Syn, D.R. Lesuer, K.L. Cadwell, O.D. Sherby, and K. Brown, "Laminated Metal Composites of Ultrahigh Carbon Steel/Brass and Al/Al-SiC: Processing and Properties," Proc. Conf. Developments in Ceranticand Metal-Matrix Conmposite's, K. Upadhya (Ed.), TMS, 311, 1991

4. D.W. Kum, T. Oyama, J. Wadsworth, and O.D. Sherby, J. Mech. Phy/s. Solids, 31, 173 (1983).
5. O.D. Sherby, S. Lee, R. Koch, T. Sumi, and 1. Wolfenstine, Materials and Manufinturing Processe's, $5,363(1990)$.

6. J. Cook and J.E. Gordon, Proc. Royyal Soc. Londom, 282, 5()8 (1964).

7. C.K. Syn, D.R. Lesuer, K.L. Cadwell, K.R. Brown, and O.D Sherby, "Processing and Testing of Metal Composites of Ultrahigh Carbon Steel/Brass Laminates and Aluminum Laminates," Engineroing Research, Dirclopment, and Techology, Lawrence Livermore National Laboratory, Livermore, California, UCRL-53868-91 (1992).

8. O.D. Sherby, T. Oyama, D.W. Kum, B. Walser, and J. Wadsworth, J. Metnls, 37, 50 (1985)

9. C.K. Syn, D.R. Lesuer, J. Wolfenstine, and O.D. Sherby, "Layer Thickness Effect on Ductile Tensile Fracture of Liltrahigh Carbon Sted-Brass Laminates," Livermore National Laboratory, Livermore, California, UCRL-JC-110413 (1992), accepted for publication in Meta!l. Trons., TMS.

10. B.P. Bonner, D.R. Lesuer, C.K.Syn, and O.D. Sherby, "Damping Measurements for Ultrahigh Carbon Steel/Brass Laminates," Proc. Symp. Damping of Multiphuse Inorganic Materinls (Chicago, Illinois), R. Bhagat (Ed.) (November 1-5, 1992); to be published by ASM International. 


\title{
Casting Process Modeling
}

\author{
Arthur B. Shapiro \\ Nuclear Test Engineering \\ Mechanical Engineering
}

In predicting the quality of a cast part, two important factors are (1) correct modeling of the fluid flow and heat transfer during the filling of a mold with a molten metal, and (2) the thermalmechanical physics of solidification and cool-down. Determining the dynamics of the flow and the free surface shape during filling are essential in establishing the temperature gradients in the melt and in the mold. Correctly modeling the physics of volume change on solidification, shrinkage on cooling, and contact resistance across the part-mold interface directly affects the cooling rate and, ultimately, the final cast shape and stress state of the cast part. This year our efforts were focused on modeling fluid fill and on the physics of solidification.

\section{Introduction}

Casting manufacturing covers a broad range, from the large tonnage of continuously cast steel products, through the intermediate-weight output of superalloy precision die castings, to the relatively small quantity of high-purity crystals. Although this project benefits modeling efforts in each of these three casting areas, we have focused on modeling precision die castings of superalloy parts.

Our approach to casting process modeling is to use the computational fluid dynamics code ProCAST' 1 to model elements of the mold-filling process, including tracking of (1) the free surface of the molten metal as it rapidly fills the mold; (2) solidification on the walls of the rnold; (3) temperature transients in the mold; and (4) temperature transients in the liquid and solidifying metal. When the mold is completely filled with liquid metal, the existing temperature field at that instant in time is re-mapped (using REMAP2) onto a new mesh for a CAST2D ${ }^{3}$ analysis to predict the final cast shape, stress state, and defects.
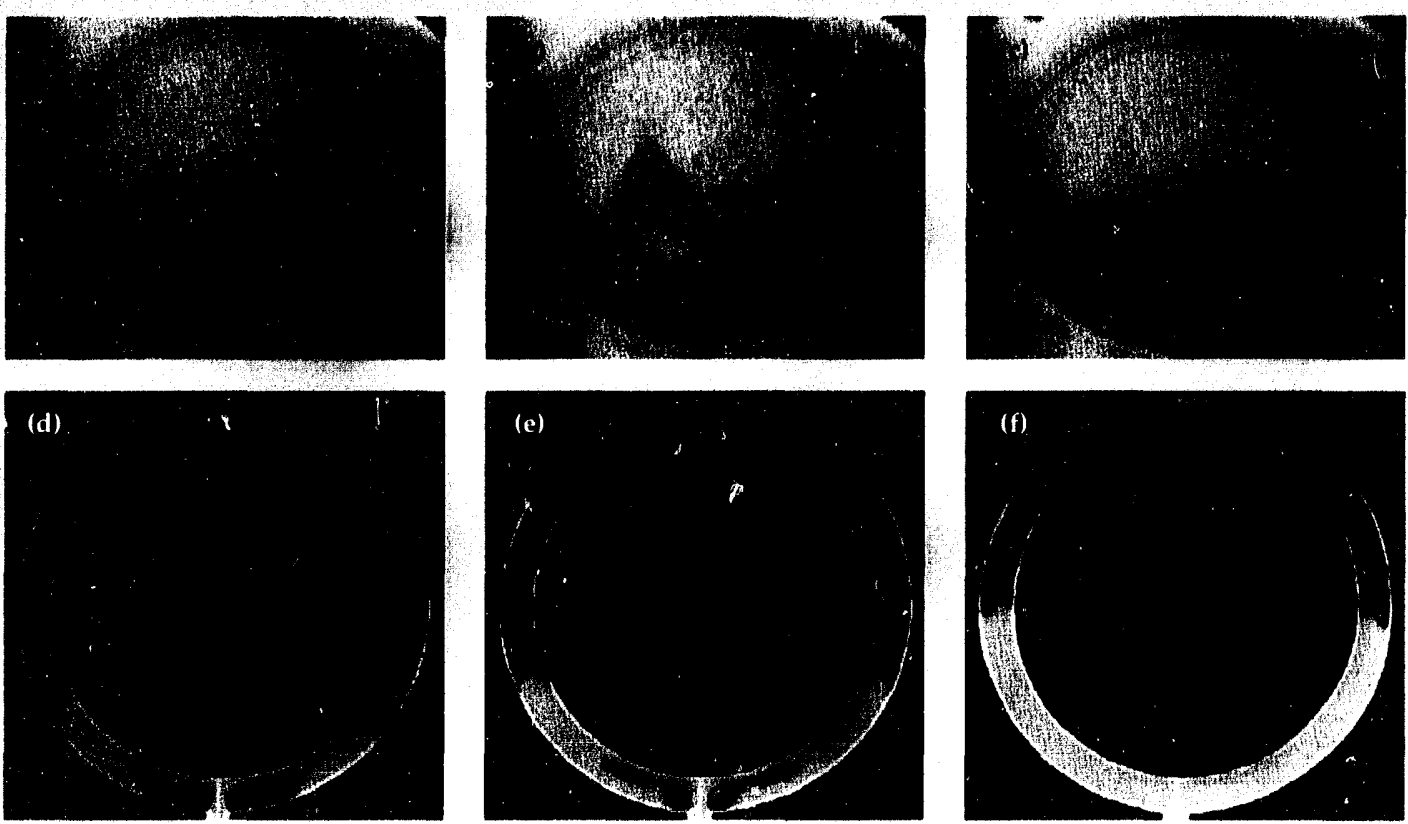

Figure 1. Experlmental $(a, b, c)$ and numerical $(d, e, f)$ results for the filling of a spherical annulus mold, with a llquild metal at 0.6, 0.9, and $1.5 \mathrm{~s}$, respectively. 

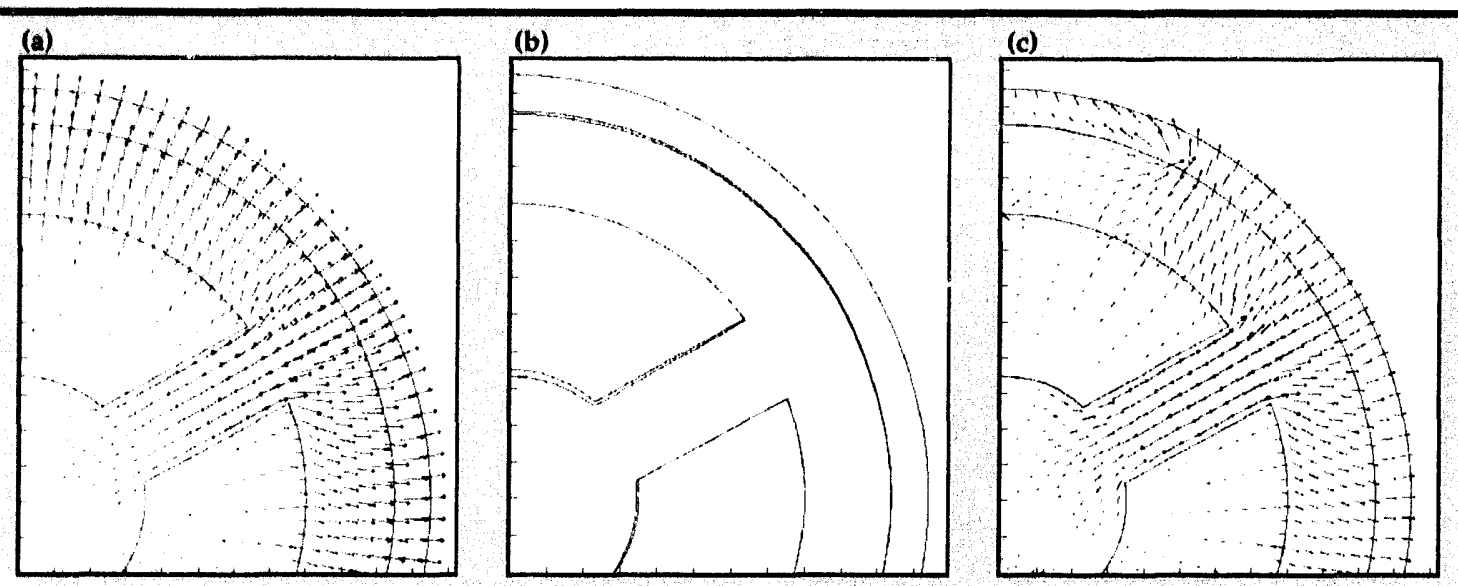

Fgure 2. (a) CAST2D calculations at an early time during cool-down, showing the heat flow paths to be radially outward. (b) At later times: gaps between the casting and mold appear due to the $-6.6 \%$ volume change of the aluminum casting on solidification and shrinkage on cool-down. (c) The direction of the heat-flux vectors, changed due to the part shrinking away from the mold on solldification. Tihe heat-flux vectors are seeking the path of least resistance to heat flow.

CAST2D models the thermal-mechanical response during cooling to room temperature including volume change on phase transformation. CAST2D also calculates thermal contact resistance across the part/mold interface.

\section{Progress}

An experimental and numerical analysis was performed to investigate the filling of a spherical mold with a liquid metal. The experiment provided visual data of the filling of the shell for comparison with the numerical calculations. The die-casting process consisted of pressurizing a pool of molten metal in a crucible and forcing the melt up a small tube to be injected into the bottom of a spherical annulus-shaped cavity. The experiment was conducted in a vacuum. The experimental data consists of a $16-\mathrm{mm}$ motion picture (24 frames per second) of radiographs of the filling of the spherical annulus. The spherical annulus filled in approximately four seconds. Figure 1 shows radiographs at three different times during the filling process. The radiographs show that initially the melt splashes fairly high up the annulus (Fig. 1a) in a nonsymmetric fashion. Although still showing considerable wave motion at later times (Fig. 1b), the melt is seen to be filling the anrulus in a more symmetric fashion. At still later times, the fill level advances evenly and symmetrically up the annulus (Fig. 1c).

ProCAST was used to numerically model the mold filling process. The spherical annulus was modeled as a two-dimensional, axisymmetric problem. Fluid properties, i.e., density, specific heat, and viscosity, were allowed to be functions of temperature. Results of the analysis are presented in Figs. 1d, 1e, and 1f. These three figures show the free surface and level of fill at the same times as the experimental results. The numerical analysis does not show the wave motion and non-symmetry at early times as observed in the experiment. However, it does show the wall jet effect as the melt enters the annulus (Fig. 1d) and a fill level that is near the average level of the experiment (Fig. 1e). At later times, when the flow is more even and symmetric, the analysis compares favorably with experiment (Fig. 1f).

We performed a fluid-thermal-mechanical analysis of the casting of a three-spoke, $38-\mathrm{cm}$ dia aluminum wheel. The liquid aluminum at $780^{\circ} \mathrm{C}$ was injected into the steel mold, which is heated to $730^{\circ} \mathrm{C}$, at a rate that fills the mold in two seconds. By forced convection, the outer surface of the mold lost heat to the environment. ProCAST was used to model the fluid-filling process. When the mold was completely filled with liquid metal, the existing temperature field at that instant in time was re-mapped onto a new mesh for a CAST2D analysis. CAST2D was used to model the thermal-mechanical response during cooling to room temperature. The aluminum undergoes phase change at $660^{\circ} \mathrm{C}$ with a volume change of $-6.6 \%$. The aluminum part is in good contact with the mold at early time. The heat flux vectors are seen to go radially outward (Fig. 2a) through the aluminum part and mold to the environment. At a later time, the aluminum has shrunk away from the mold due to volume shrinkage on solidification, and gaps have opened up (Fig. 2b). The heat-flux paths 
shown in Fig. $2 c$ are seen to be considerably changed from the pattern of Fig. 2a. The direction of the heat-flux vectors has changed while seeking the path of least resistance to heat flow.

\section{Future Work}

In the future, we plan to develop a closely coupled fluid-thermal-mechanical code to be used for analysis of casting problems. Numerical modeling in the areas of fluid fill, solidification physics, and material constitutive development must be refined for such a code to be useful in casting process modeling. We also plan to conduct experiments for code validation.

1. ProCAST ${ }^{T M}$ Llser's Mammal Version 2.(), UES, Inc., 4401 Dayton-Xenia Road, Dayton, Ohio 454321894.

2. A.B. Shapiro, REMAP-A Computer Code Thut Transfers Note Information Betueen Dissimilar Grids, Lawrence Livermore National Laboratory, Livermore, California, UCRL-ID-104090(1990).

3. A.B.Shapiro, CAST2D-A Finite El'ment Computer Code for Casting Process Modeling, Lawrence Livermore National Laboratory, Livermore, California, UCRL-MA-108598 (1991). 


\section{Characterizing the Failure of Composite Materials}

\author{
Scott E. Groves, \\ Roberto J. Sanchez, \\ William W. Feng, and \\ Albert E. Brown \\ Engineering Sciences \\ Mechanical Engineering
}

\author{
Steven J. DeTeresa \\ Richard E. Lyon \\ Materials Division \\ Chemistry and \\ Materials Science Department
}

Our goal for this project has been to characterize the three-dimensional (3-I)) performance of continuous-fiber polymer composite materials, by developing new experimental and theoretical methods. This report highlights our major accomplishments: (1) multiaxial testing of composites; (2) the development of a new composite-failure criterion; (3) the development of ORTHO3D, a 3-D orthotropic finite element code; (4) the dynamic testing of composites; and (5) a helical compression study of filament-wound composite tubes.

\section{Introduction}

This project has helped to develop carbon-fiber composite materials for use in penetrating warhead cases, gun barrels, advanced munition components, projectiles, nuclear weapons, SDI, and high-energy-density flywheels.

We have had the opportunity to jointly pursue some of this work with various research and development centers of the U.S. Army and Navy, as well as with various contractors in private industry. The primary reason for selecting carbon-fiber composite materials is their high specific strength and stiffness. Other factors influencing design include low ' $Z$ ' material composition, low coefficient of thermal expansion, impact resistance, and fire safety.

These materials are generally limited not by their performance capabilities but by our lack of understanding and ability to model their complex 3 -D response. Our research effort has made great strides in providing the necessary tools and information to optimize these designs.

\section{Progress}

Our major accomplishments have been (1) multiaxial testing of composites; (2) the development of a new composite-failure criterion; (3) the devel- opment of ORTHO3D, a 3-D, orthotropic finite element code; (4) the dynamic testing of composites; and (5) a helical compression study of filament-wound composite tubes.

\section{Multiaxial Testing of Composites}

Our most important accomplishment has been the development of a unique multiaxial test system

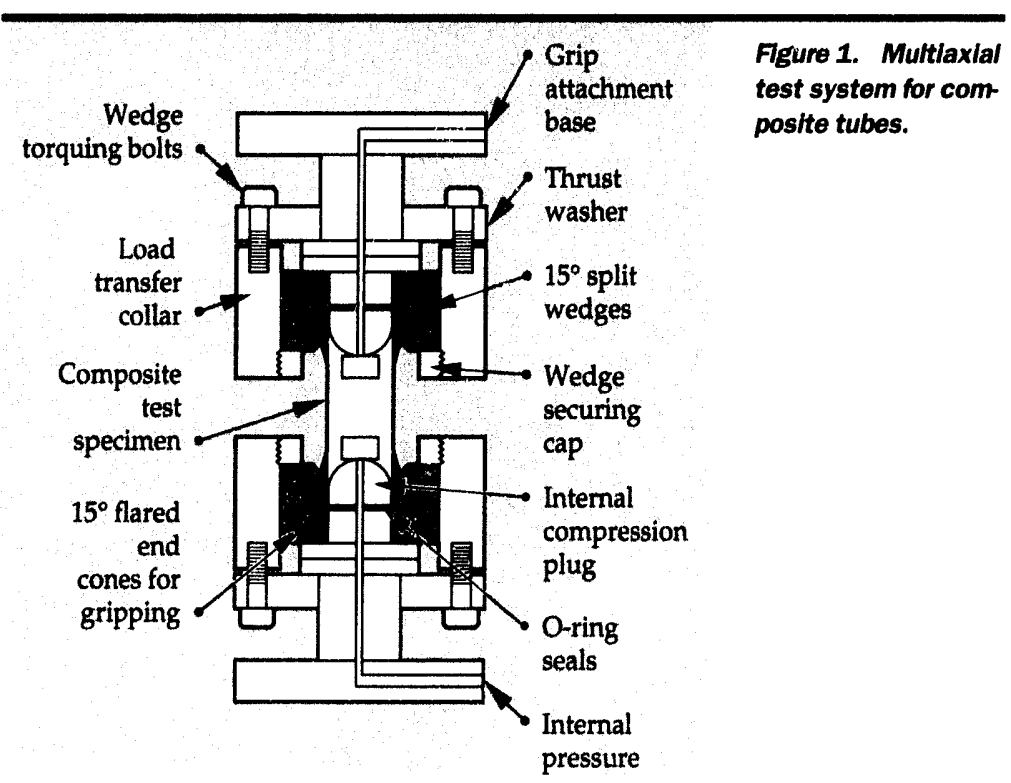




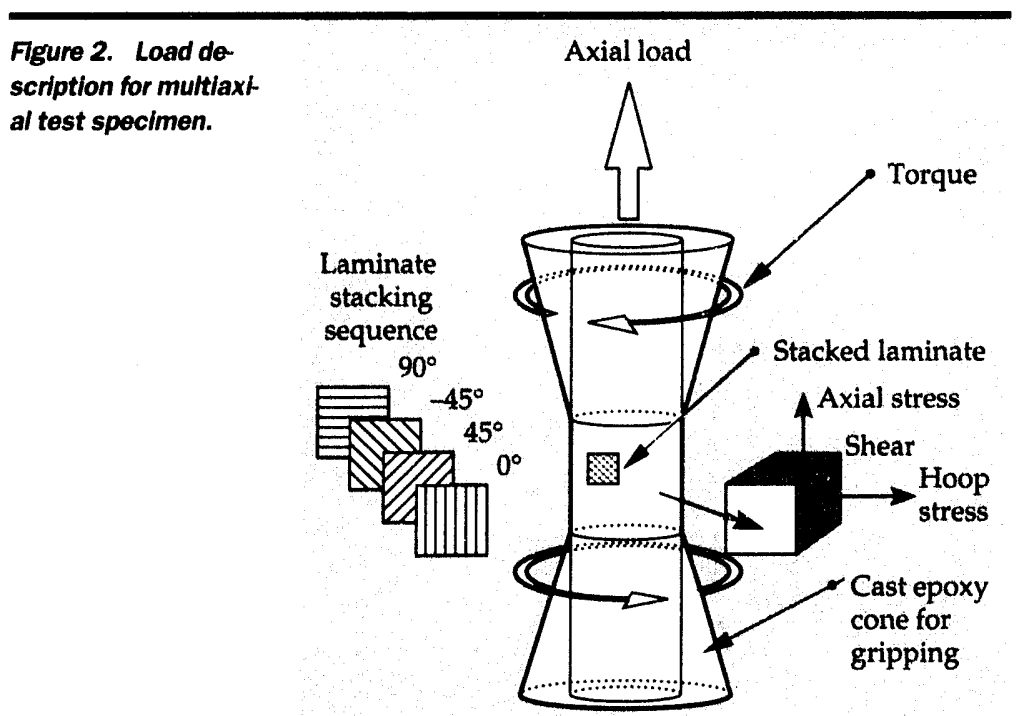

Figure 3. Multiaxial fallure sunface for a filament-wound Toray 1000/ DER332-T403 \pm 1.5 $\pm 45, \pm 89$ ] carbon/ epoxy laminate.

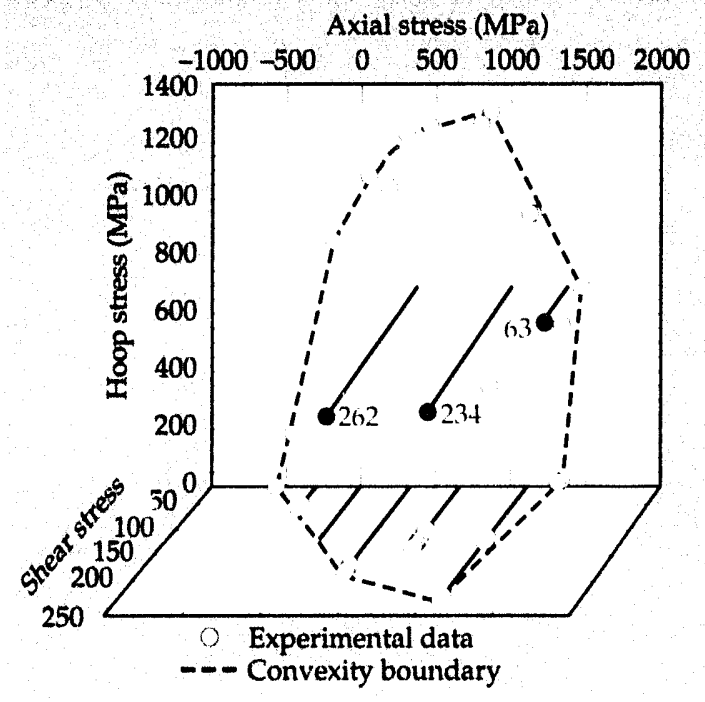

for polymer composite materials. I This technique allows testing of 2 -in.-dia composite tubes under a combination of axial, torsion, and intemal pressirization. The unique advancement with this system is the simple but effective gripping mechanism that incorporates a $15^{\circ}$-potted epoxy cone for providing a smooth transition in load between the grip and the test specimen. The test specimen itself is a straightwalled composite tube. Diagrams of the multiaxial grip and test specimen are shown in Figs. 1 and 2. This test system has provided Lawrence Livermore National Laboratory (LLNL) with an unrivaled capability to generate multiaxial failure data for polymer composite materials.

The most extensive multiaxial failure surface that was generated with this system is shown in Fig. 3. The material system used in this study consists of the Toray 10)(0G carbon fiber having a 95()-ksi tensile strength, impregnated with DER3.32-
T403 epoxy having a tensile strength of $10 \mathrm{ksi}$. This material system has been used in the majority of the composite structures we have designed and fabricated.

The multiaxial gripping concept has lead to the development of an efficient high-strength shear joint for split composite pressure vessels and for modular composite gun barrels. We have also successfully scaled up the gripping system to test 9-in.-dia composite tubes under axial load. The biggest use of this system, however, has been focused on the optimization of the compression performance of filament-wound tubular structures, such as those used for composite penetrators, projectiles, and support structures.

\section{New Composite-Failure Criterion}

In this project, we have developed a new failure criterion for composite materials, the 'Feng failure criterion. 2 The failure criterion is written in terms of the strain invariants in finite elasticity. These invariants are written as functions of the Cauchy strains and the deformation gradients. Among these strain invariants, two are functions of the fiber orientation, and three are not. Therefore, the failure criterion can be further divided into two modes, the fiber-dominated failure mode and the matrix-dominated failure mode. The criterion contains five failure material constants for infinitesimal, general, 3-D strain states.

In the criterion, there are three quantities governing the failure surface in composites: the distortional energy, the dilational energy, and the difference between compressive and tensile strengths. The minimum number of constants required is three for each failure mode. Therefore, this failure criterion represents the minimum number of constants required for determining the failure surface of composites for the second-order strain-failure criterion.

We have previously obtained the unidirectional lamina failure surface for Toray $10(00 /$ DER332T4(0) carbon/epoxy fiber composites. ${ }^{3}$ In this project, we have obtained experimentally the fundamental material properties for this unidirectional composite, both elastic constants and strength. The corresponding strengths obtained by the Feng failure criterion for symmetrically balanced angleply laminates, is shown in Fig. 4. The results show that the Feng criterion predicts the fiber- and matrix-dominated failure modes. Furthermore, for Toray $10(0)$ /DER332 symmetrically balanced angle-ply laminates subjected to uniaxial load, the initial failure consistently initiates in the matrix. 


\section{Development of ORTHO3D}

During the second year of this program, we began an effort to develop a simple, 3-D, orthotropic finite element program for the evaluation of composite failure criteria. This algorithm has become known as ORTHO3D and has been developed under a university contract with Texas A\&M University. ${ }^{4}$ In all, five failure criteria have been implemented: maximum stress, maximum strain, Tsai-Wu, Hashin, and the Feng failure criterion.

To perform accurate failure modeling of a laminated composite structure, ORTHO3D was written to permit detailed sub-lamina (single-ply) analysis of generic structures such as cylinders and cubes. These two generic shapes represent characteristic local volumes of larger structures such as penetrator missile cases or thick larninated plates. Performing this level of analysis explicitly with NIKE3D or DYNA3D is too cumbersome to be cost effective. Furthermore, large structural analysis codes like NIKE cannot simultaneously model the global behavior of a structure and model the characteristic local volume in sufficient detail to perform accurate local-failure analysis (local/global modeling).

ORTHO3D, which is written in Fortran, is operational on a variety of computer platforms, including Macintosh, SUN, Vax, and IBM. The size of problems (local volume) that one can solve is limited only by computer memory. Even small local volumes require an astonishingly large amount of memory. Typically, a single ply is $0.005 \mathrm{in}$. thick, and the local volume is composed of many of these layers. Generally, we recommend a minimum of three elements (8-noded brick elements) througl: the thickness of each ply to capture representative local stress/strain behavior. Maintaining a respective aspect ratio $(<10)$ for each element, the number of elements required to model a local volume can be very large. At 8 nodes per element and 3 degrees of freedom per node, the memory requirements can quickly exceed most small computers. Typical local volumes that we have solved require 2) $\mathrm{Mb}$ of ram. Efforts over the last year have focused on minimization of memory requirements via more efficient equations solvers, nodal number schemes, and array sharing.

To facilitate the 3-D modeling of composite structures, ORTHO3D was adapted to generate the effective, 3-D, homogenized properties for the characteristic local volumes required by NIKE for analysis of large (global) composite structures. The homogenized 3-D properties are considered more representative of the actual structural behavior of

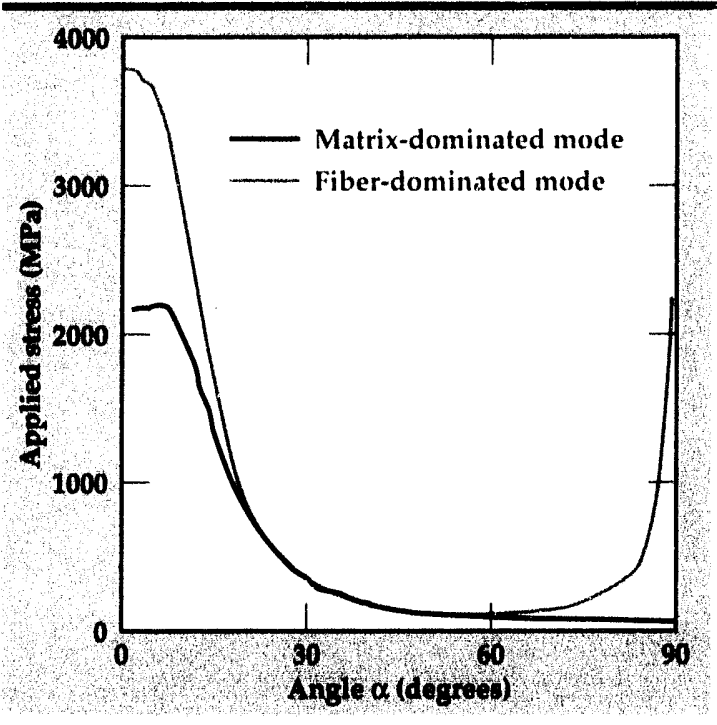

Figure 4. Fallure strengths predicted by the finite-strain-invariant fallure criterton for Toray 1000/ DER332 symmetr. cally balanced anglo ply laminates.

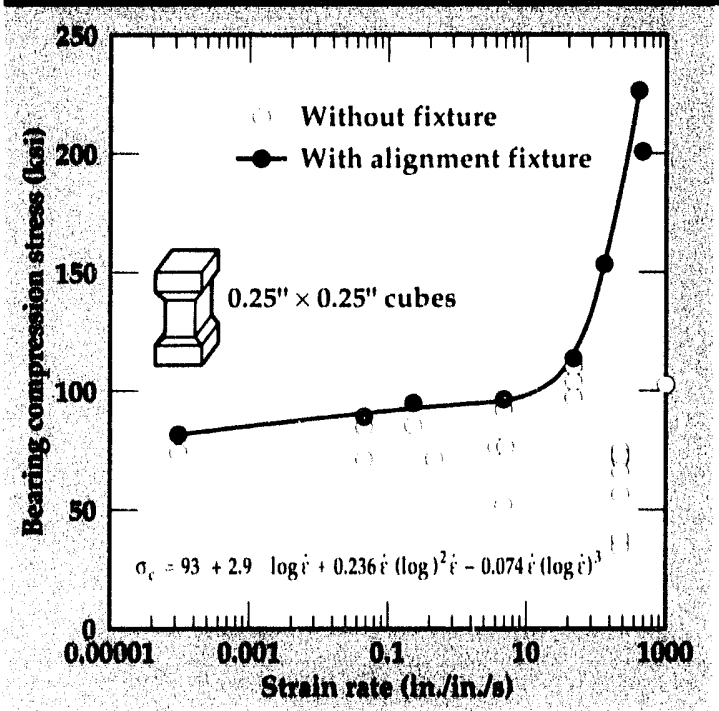

Figure 5. High strain-rate-bearing compression of IM6/974 [0,90] tapered cubes. the local volume than those properties predicted by available, 3-D, micromechanical constitutive solutions. Once NIKE solves the structural problem, the local traction set can be passed to ORTHO for detailed failure analysis.

\section{Dynamic Testing of Composites}

To provide design support of the composite penetrators, gun barrels, and projectiles being developed at LLNL, we have evaluated and developed a variety of new high-strain-rate testing techniques for polymer composite materials. 5 Prior to this investigation, an extremely limited data set was available on the high-strain-rate response of polymer composites. We have successfully generated strain rate data from $(0 / \mathrm{s}$ to $3000 / \mathrm{s}$ in compression and $0 / \mathrm{s}$ to $100 / \mathrm{s}$ in tension, using a variety of test machines. Our of- 


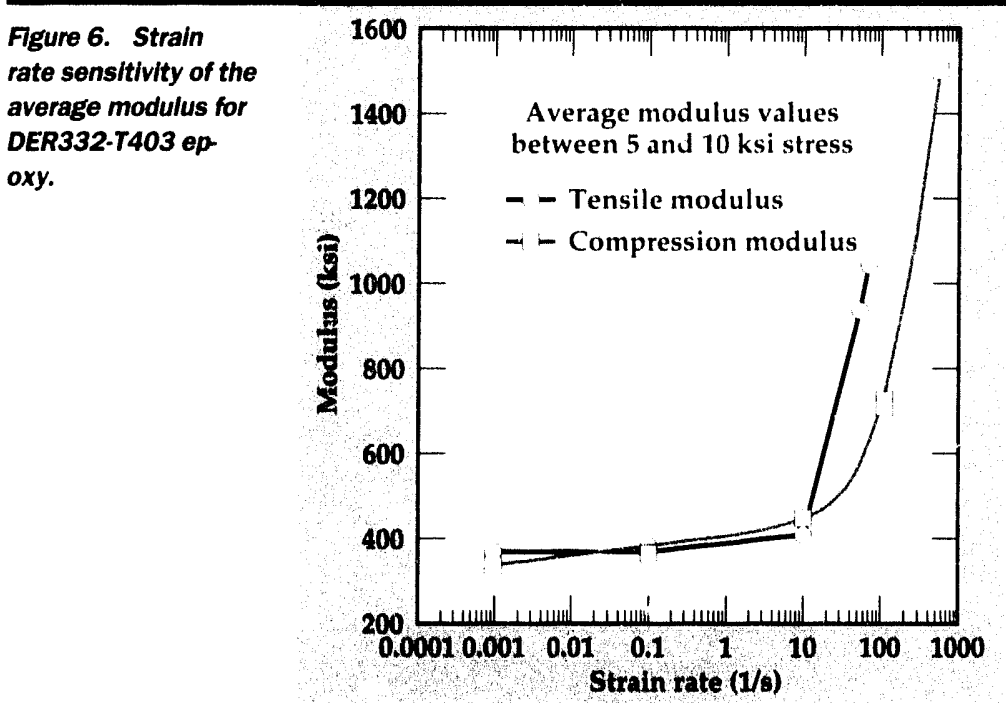

Fgure 7. Strain rate sensitivity effects on the compressive fiow stress for three epoxy resins.

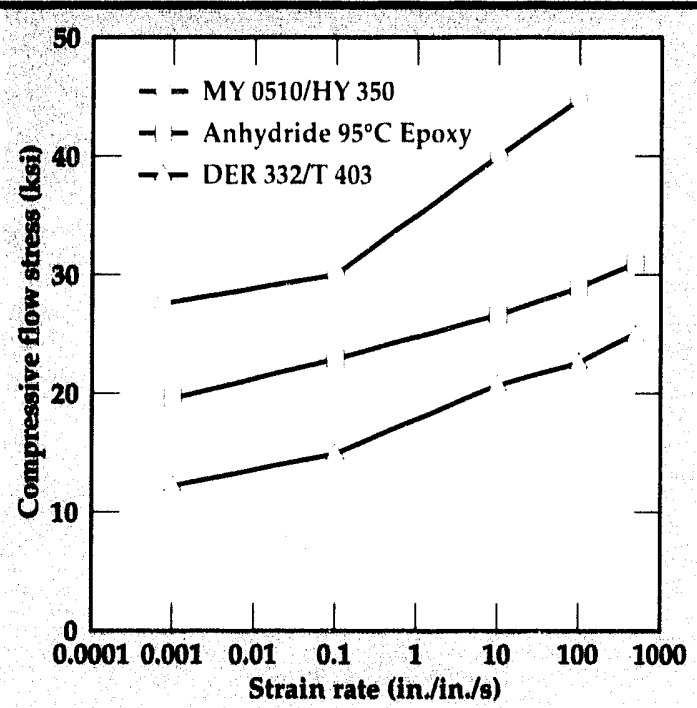

forts have yielded some very interesting and encouraging material responses.

Most of our efforts focused on developing an acoustically damped, high-energy drop tower for evaluating the high-strain-rate compressive performance of composite materials. Three major advances eccurred to the drop tower system that created a highly capable material-evaluation system. First, an acoustically darnped base system was installed that eliminated spurious shock waves

Table 1. Basic epoxy properties.

\begin{tabular}{|c|c|c|c|c|c|}
\hline Epoxy System & $\mathbf{G}_{\mathrm{m}}$ & $\begin{array}{l}\text { s, flow }_{\text {c, flow }} \\
\text { (ksi) }\end{array}$ & $t_{y}$ & $\mathrm{~T}_{\mathrm{g}}$ & $\begin{array}{c}\text { Viscosity } \\
\text { (P) }\end{array}$ \\
\hline DEER3332-T4()3 & 160 & 12 & 6.5 & 9() & 7.8 \\
\hline Anhydride & 180 & 18 & 8.7 & 14() & 3.4 \\
\hline MY051()-11Y350 & 2015 & 28 & 10.7 & 180 & 14 \\
\hline
\end{tabular}

that were convolved with the quartz load cell data. Second, a high-speed data-acequisition system was developed that significantly automated data gathering and reduction. Third, a precision alignment fixture was developed along with precision-machined test specimens, which resulted in a significant improvement in the measured mean strength of the composite materials as well as minimized data scatter.

Three interesting results from our efforts are presented. All of our experimental results indicate an increase in ooth strength and modulus with increasing strain rate. First, the bearing compression strength of a $[0,90]$ laminated composite material is presented in Fig. 4. 'This result reveals a significant strengthening (occurring at strain rates above $10 / \mathrm{s}$. An examination of neat resin behavior revealed similar trends. Figure 5 shows the change in neat resin modulus as a function of strain rate. Finally, Fig. 6 shows strain-rate sensitivity effects on the compressive flow stress of three different epoxy resin systems being evaluated at LLNL.

\section{Helical Compression Study of Filament- Wound Composite Tubes}

During the last year of this program, an evaluation of the compressive performance of helically wrapped carbon/epoxy tubes ${ }^{\text {th }}$ was performed using the three different epoxy resins shown in Fig. 6. The objective of this study was to optimize the compression performance of filament-wound composite structures. Table 1 lists the basic properties of these systems that influence the compression strength of composites. The last two columns in Table 1 are processing parameters.

The compressive strength of a unidirectional composite material is controlled by the properties of the matrix surrounding the fibers. It has been argued that compression of unidirectional composites is a micro-buckling controlled event in the fibers, and thus dependen'. on factors such as the local shear modulus of the matrix. What we were hoping to find was an improvement in compression strength of helical composite tubes fabricated with the MY(051()-HY350) epoxy system.

Figure 8 shows the variation in axial compression strength for Toray 700$)\left|89, \pm \theta_{2},-89\right|$ helically wrapped composites tubes as a function of helical angle, $\theta$. These tests were conducted using the multiaxial gripping system. The MY(0510) system might be considered to be stronger, but the ervidence is not conclusive. $A$ problem with polymer composite materials is that it is impossible to isolate single variables. The viscosity of the epexy 


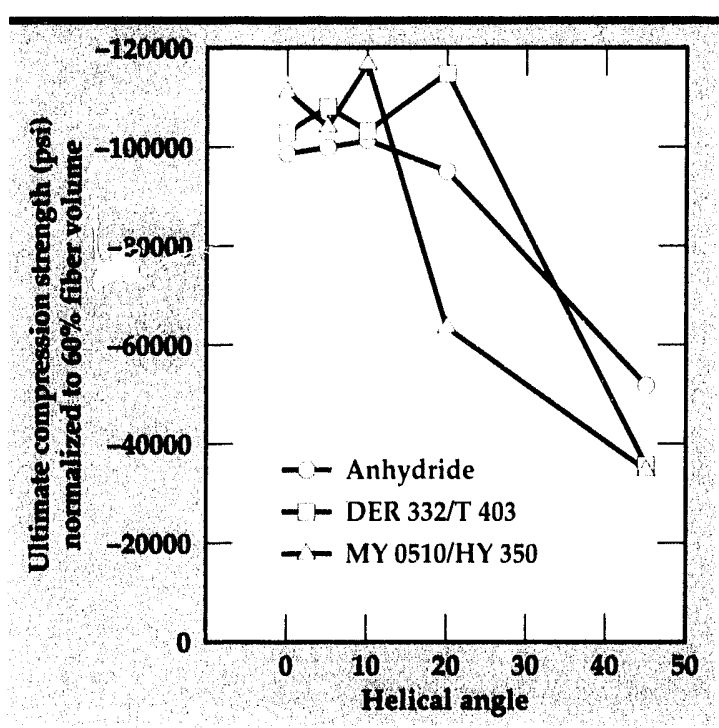

Figure 8. Normalized axial compression strength for T700 $[89, \pm \theta,-89]$ hellcally wrapped carbon/epoxy tubes with three different matrices.

turned out to be a major factor as well. The MY0510 system has a much higher viscosity than either the Anhydride or DER332 epoxies, which makes it very difficult to process. This resulted in a composite material with higher void contents and resinrich areas. In contrast, the Anhydride epoxy system produces very high quality composite materials.

A somewhat surprising result was the small variation in compression strength at helical angle between $0^{\circ}$ and $10^{\circ}$. Again, processing influences these results; it is very difficult to achieve uniform part quality for helical winding angles less than $10^{\circ}$. Furthermore, helical angles greater than $10^{\circ}$ are much faster (cheaper) to fabricate.

\section{Future Work}

We have secured. a long-term Cooperative Research and Development Agreement with Boeing Commercial Airplane Group to study the "Strength and Durability of Continuous Fiber Polymer Composites." Natural extensions of our past efforts in
"Characterizing the Failure of Composites" will be to modify ORTHO3D to model long-term thermal-viscoelastic effects for these materials. The multiaxial test specimen developed in this program has been selected as a prime test specimen for long-term fatigue testing because of the lack of a free edge associated with the cylindrical test specimen. Finally, we will continue to support the LLNL weapons-related activities in composites, especially in the area of compression optimization, that will make significant use of the multiaxial test specimen.

1. S.E. Groves, R. Sanchez, and W.W. Feng, "Multiaxial Failure Characterization of Composites," Composites: Design, Manufacture, and Application, S.W. Tsai and G.S. Springer (Eds.), Proc. 8th Int. Conf. Composite Materials (published by SAMPE), (July 1991).

2. W.W. Feng and S.E. Groves, On the Finite Strain Invoriant Fuilure Criterion for Composites, Lawrence Livermore National Laboratory, Livermore, California, UCRL-JC-104825 (1990); accepted for publication in J. Compos. Mater.

3. W.W. Feng and S.E. Groves, I. Advanced Composite's Letters 1 (1), 6(1992).

4. M.A. Zocher, D.H. Allen, and S.E. Groves, "Predicted Stiffness Loss Due to Delamination in Filament Wound Composite Cylinders," Composites: Design, Mamufacture, and Application, S.W. Tsai and G.S. Springer (Eds.), Proc. 8th Int. Conf. Compos. Mnter. (published by SAMPE), (July 1991).

5. S.E. Groves, R.J. Sanchez, R.E. Lyon, and A.E. Brown, "High Strnin Rate Effects for Composite Materials," Lawrence Livermore National Laboratory, Livermore, California, UCRL-JC-107836 (1992); accepted for publication in ASTM Composite Materials: Testing and Design (1992).

6. S.E. Groves, R.J. Sanchez, and S.J. DeTeresa, "Evaluation of the Compressive Performance of Helically Wrapped Carbon/Epoxy Tubes with Three Different Epoxy Matrices," presented at the ASTM Symposium: Compression Response of Composite Structures, Miami, Florida (November 16-17, 1992). 


\section{Fiber-Optic Raman Spectroscopy for Cure Monitoring of Advanced Polymer Composites}

\author{
Richard E. Lyon \\ Materials Division \\ Chemistry and Materials \\ Science Department
}

\author{
Thomas M. Vess and \\ S. Michael Angel \\ Environmental Sciences Division
}

\author{
M.L. Myrick \\ Department of Chemistry \\ University of South Carolina \\ Columbia, South Carolina
}

The curing reaction of an epoxy resin matrix that is used for wet-filament-wound composites was monitored using Raman spectroscopy measured over fiber optics. The resin system consists of the diglycidyl ether of bisphenol-A in combination with a polyethertriamine hardener in a 1:1 stoichiometric ratio. The extent of chemical reaction of the epoxy as a function of time was measurable through changes in peak heights of several vibrational modes. A Raman peak associated with a phenyl ring vibration in the epoxide component was used as an internal reference to correct for density changes and instrumental variations. The feasibility of simultaneous temperature measurements was successfully demonstrated with the same fiber optics used to obtain the cure chemistry data, by measuring the intensity of anti-Stokes Raman scattering from the epoxy.

\section{Introduction}

Although significant improvements in the performance of fiber reinforcements and polymer matrix materials have been achieved in the past decade, composite processing technology has not kept pace with these advances. Consequently, high-performance material properties are not realized in composite parts fabricated using current processing methods, and manufacturing costs are high. 'Smart' processing of thermoset matrix composites could dramatically reduce manufacturing costs by reducing the rejection rate and improving part quality, through cure cycle optimization and 'on the fly' process adjustments to account for variations in the chemical composition of the starting materials. Unfortunately, commercially available cure sensors for automated control are currently limited to dielectric ${ }^{1,2,3}$ or ultrasonic ${ }^{4}$ measurements, which sense only mechanical property changes in the resin and cannot provide a direct measure of the cure chemistry in the composite. Furthermore, recently proposed fiber-optic spectroscopic sensors using mid-infrared ${ }^{5,6,7}$ or ultraviolet-visible ${ }^{8,9}$ wavelengths are either prohibitively expensive and yield little or no additional information when compared with commercially available cure sensors, or contain a large number of spectral interferences that make data interpretation difficult, if not impossible. ${ }^{10}$

Raman spectroscopy is an established technique for the analysis of polymers, ${ }^{11,12,13}$ chemical reactions, ${ }^{14}$ and thermosetting polymer composite cure reactions. ${ }^{15,16}$ It has many advantages over mid- 
Figure 1. Experimental arrangement for dual-fiber probe geometry. Inset emphasizes sample location. M: spectrograph, $D$ : detector, L: lens, S: laser source, FO: fiber optic, F: filter.

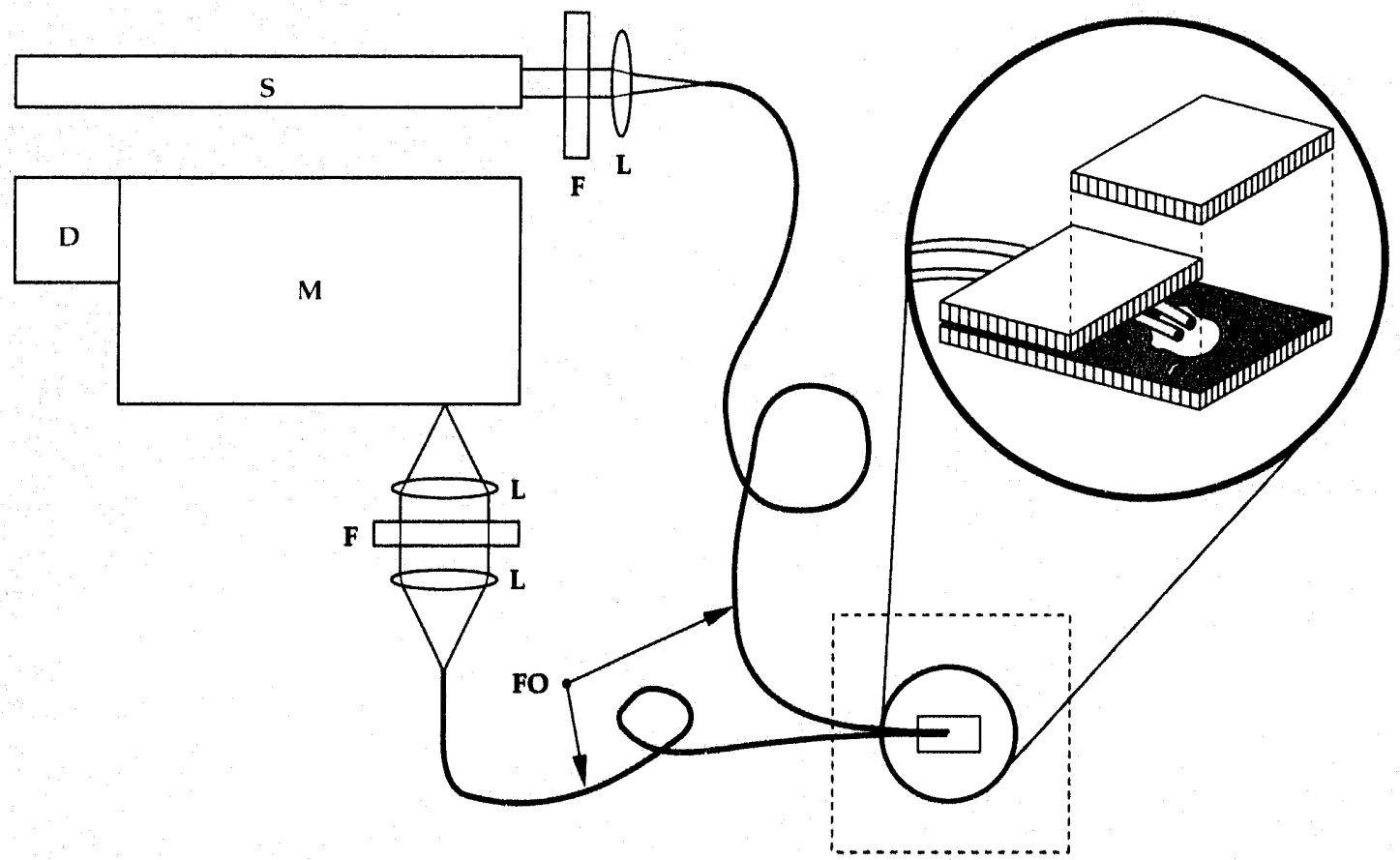

infrared absorption and UV-visible fluorescence spectroscopies for polymer composite cure monitoring, including broader applicability, potentially higher sensitivity and selectivity, as well as the freedom from large background corrections caused by fiber absorption. Moreover, Raman spectroscopic measurements can be conducted remotely and ill situ using rugged, inexpensive, fused silica optical fibers (available from domestic suppliers) and economical, dioxde laser-excitation sourcescommonly used in communications and electronic equipment. ${ }^{17}$ Subsequent to monitoring the cure reaction of the composite matrix, the quartz optical fibers could be used as embedded strain or damage sensors, or used for monitoring chemical degradation or moisture absorption of the resin.

\section{Progress}

During FY-92, the first year of the project, Raman-active vibrational bands in epoxy resins were identified, and tentative band assignment: were made for the epoxide functional group and the phenyl ring backbone, from model compound studies. Cure monitoring of standard epoxy resins was demonstrated using several meter lengths of 20()- $\mu$ m-dia quartz optical fiber using cither singlefiber or dual-fiber probes. ${ }^{18}$ The single-fiber probe experiments were discontinued due to problems with high fiber background and the inability to accurately correct the data. The utility of economical near-intrared (NIR) diode lasers as excitation sources for cure monitoring was demonstrated in comparison studies with a conventional Ti-sapphire laser operating at $819-\mathrm{nm}$ wavelength. We also demonstrated for the first time the proportionality between Raman peak ratios and epoxide group concentration in full density epoxide resins, validating the Raman scattering technique for thermoset resin cure monitoring.

\section{Experimental}

The epoxy system studied was a 1:1 stoichiometric ratio of diglycidyl ether of bisphenol-A resin (DER 332, Dow Chemical) and a polyoxypropylene triamine hardener (Jeffamine T-4)3; Texaco Chemical) in a weight ratio of $100 / 45 \mathrm{resin} /$ hardener. A detailed characterization of this epoxy has been reported olsewhere, 14,21

The dual-fiber probe experiment is shown in Fig. 1 and has beendescribed in detail elsewhere. ${ }^{\text {I }}$ Dual-fiber Raman probes consist of two fibers, side-by-side, cemented in place between two microscope slides so as to meet at an angle of approximately 15, with the polished probe ends of the fibers extended several millimeters beyond the top slide, as shown in the inset of Fig. 1. One fiberoptic was used to transmit the laser to the epoxy sample, while the other was used to collect the Raman scattering from the sample and transmit it to the detection system. Dual-fiber probecure measurements were made by thoreughly mixing the liquid epoxy components, and then adding a drop 
of the epoxy mixture to the probe tip so as to completely cover the sensor. No effort was made to de-gas the epoxy before injection. Some air bubbles appeared during processing, but these did not appear to affect the signal quality. A cover slide was then placed over the probe area, using spacers to provide a 2-mm gap filled with epoxy, and the entire assembly was placed in a temperature-controlled oven.

\section{Results and Discussion}

Separate Raman measurements of the DER 332 resin and Jeffamine T-403 hardener components revealed that the resin component scattering was approximately three to five times as intense as that of the hardener, so that in the $100 / 45 \mathrm{w} / \mathrm{w}$ ratio used for the epoxy cure studies, the resin scattering is dominant. Figure 2 shows a series of in situ spectra obtained during a typical epoxy curing. These spectra are averages of spectra accumulated over several minute intervals. Measurements at one-second intervals yielded comparable results and confirm the potential of this technique for realtime cure monitoring. One major peak near $1112 \mathrm{~cm}^{-1}$ remains relatively constant during the curing process and can be used as an internal standard to correct for fluctuations in the sample density, clarity, refractive index, and instrumental factors during measurement. This peak has been associated with an asymmetric breathing vibration of the aromatic rings in the diglycidyl ether of bisphenol-A epoxide resin. Several peaks disappear or shift during the curing process, while several new peaks appear. The most obvious change is in the peak located near $1240 \mathrm{~cm}^{-1}$. This peak loses much of its intensity during the cure and can be assigned to a stretching vibration of the epoxide ring. Although all of the peaks appeared to change

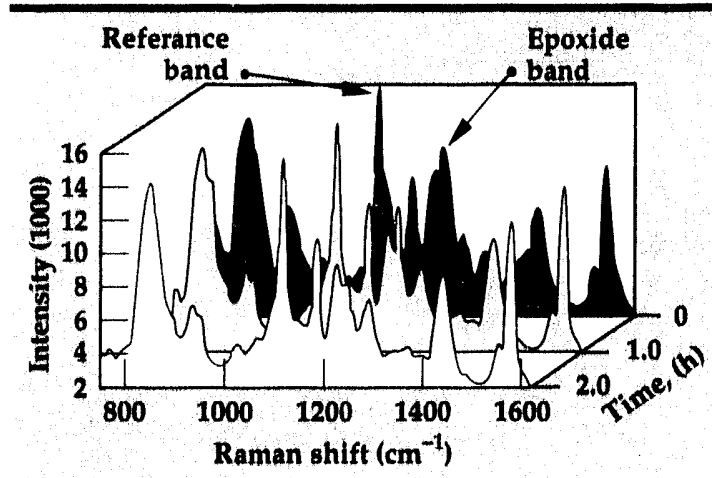

Figure 2. Series of corrected, dual-fiber probe, Raman spectra for the epoxy, taken immedlately after mixing (black), $1.2 \mathrm{~h}$ at 75 (gray), and $2.2 \mathrm{~h}$ at $75 \mathrm{C}$ followed by a 1-h post-cure at $90 \mathrm{C}$ (white).

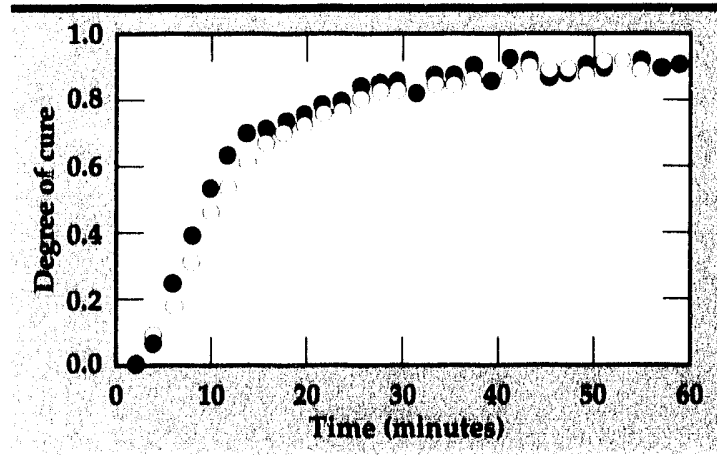

Figure 3: Isothermal degree of cure $(\alpha)$ for epoxy at $90^{\circ} \mathrm{C}$ vs time. Solld and open circles are data from dlodo-laser and Tl:Sapphiro-laser Raman experiments, respectlvely. in absolute intensity, probably in response to the changing density of the epoxy as it cures, the ratios of the $1240 \mathrm{~cm}^{-1}$ peak to the $1112 \mathrm{~cm}^{-1}$ peak decrease smoothly as a function of time.

Figure 3 is a plot of two sets of Ramari data for degree of cure, $\alpha(t)$, vs time for an isothermal cure at $90^{\circ} \mathrm{C}$. Both experiments used the $2-\mathrm{mm}$ sample thickness, dual-fiber probe arrangement; however, one experiment used a Ti:sapphire laser while the other used a diode laser. The agreement between the duplicate cure experiments is seen to be excellent, indicating a high degree of reliability for the technique. Moreover, the trend of $\alpha$ vs time closely approximates previously published degreeof-cure data for this same DER 332/T-403 epoxy, ${ }^{19}$ using NIR absorption spectroscopy ${ }^{10}$ at slightly different stoichiometry, temperature, and sample thickness.

In addition to the peak height changes, the peaks were seen to shift to lower energy as the cure progressed. The total shift was small (approximately 5 to $20 \mathrm{~cm}^{-1}$ ), but was reproducible. A study performed on a previously cured sample showed no change in vibrational frequency with temperature. Consequently, the peak shift to lower energy during cure is not simply a thermal phenomenon, but may be caused by a change in

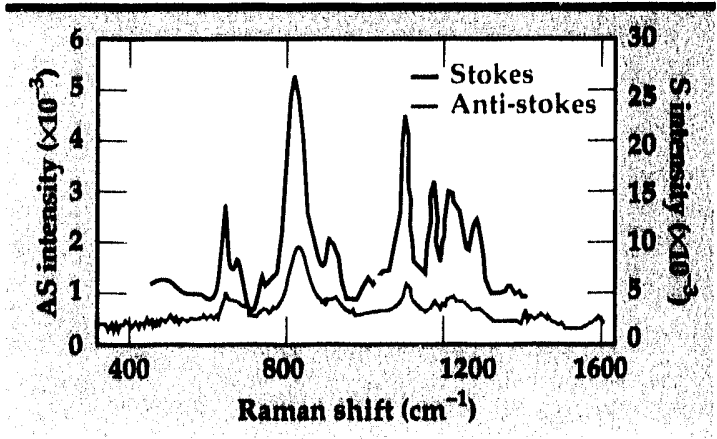

Figure 4: Ant/-Stokes Raman spectrum of the cured epoxy, superimposed on Stokes Raman spectrum for a tempera ture of $100^{\circ} \mathrm{C}$. 
the local environment as the curing process occurs. For example, the increase in viscosity during the curing process may stiffen the local environment and mix the vibrations of the individual monomers more strongly with low frequency bulk vibrations. If this is the case, it is conceivable that this phenomenon could be used as a measure of local viscosity, but this possibility has not yet been tested.

The measurement of sample temperature by comparison of Stokes and anti-Stokes Raman scattering (see Fig. 4) is straightforward and readily accomplished. The theoretical ratio of the intensities of the anti-Stokes $\left(\mathrm{I}_{\mathrm{AS}}\right)$ and Stokes $\left(\mathrm{I}_{\mathrm{S}}\right)$ scattering is

$$
\frac{\mathrm{I}_{\mathrm{AS}}}{\mathrm{I}_{\mathrm{S}}}=\left[\frac{v(0)+v(\mathrm{i})}{v(0)-v(\mathrm{i})}\right]^{4} \exp \left\{\frac{-\mathrm{hc} v(\mathrm{i})}{\mathrm{kT}}\right\}
$$

where $v(0)$ is the laser frequency; $v(i)$ is the vibrational energy of the $\mathrm{i}$-th mode; and $\mathrm{h}, \mathrm{c}$, and $\mathrm{k}$ are Planck's constant, the speed of light, and Boltzmann's constant, respectively. For the epoxy system studies here, a plot of the natural logarithm of $\mathrm{I}_{\mathrm{AS}} / \mathrm{I}_{\mathrm{S}}$ (using the $829 \pm 3 \mathrm{~cm}^{-1}$ vibrational mode) against the inverse temperature, $1 / \mathrm{T}$, for temperatures ranging from $\mathrm{T}=294$ to $455 \mathrm{~K}$ yielded a straight line with a slope of $1200 \mathrm{~K}$, an intercept of 0.517 , and a correlation coefficient of 0.997 . This calibration curve can now be used to determine the in situ temperature of the resin system at any given time during a cure cycle. The precision of temperature measurements is limited by the signal-to-noise ratio of the much weaker anti-Stokes peak ( $S / N \approx 20$ in Fig. 4). An uncertainty in temperature, $\Delta T \approx \pm 5 \mathrm{~K}$, at $373 \mathrm{~K}$ is estimated from the relationship, $\Delta T=T^{2} /[B(S / N)]$, obtained by differentiation of Eq. 1, where $B$ is the slope of the line. However, the accuracy of temperature measurements can be improved over the results described here, by using high-performance optical filters and also by using longer integration times.

In summary, fiber-optic Raman spectroscopy can be used for remote, in sill monitoring of the reaction chemistry and temperature of epoxies used as matrix materials in fiber composites during the cure cycle. While single-fiber probes were found to suffer from fiber-background effects, dualfiber probes having dimensions on the order of $200 \mu \mathrm{m}$ have been demonstrated successfully. Moreover, the quality of the spectra obtained for the epoxy is sufficient to warrant use of the dual- fiber Raman probe as an in situ quality control technique prior to cure monitoring.

\section{Future Work}

Future work will focus on (1) refining and miniaturizing the sensor; (2) evaluating the Raman fiber-optic technique for monitoring other thermoset polymer cure chemistries; (3) performing measurements in thermoset matrix fiber composites; and (4) developing simultaneous, multi-point sampling capability. Based on the preliminary results presented in this paper, we feel that in combination with compact new instrumentation and economical diode-laser excitation sources, fiberoptic Raman spectroscopy can be used to configure a rugged process monitoring and control system for an automated, polymer composite production environment.

\section{Acknowledgements}

The authors would like to express thanks to Gerald Goldstein of the Office of Health and Environmental Research (RPIS No. 003906) for supporting a part of this research, and to Katherine Chike of the University of South Carolina for experimental work in validating this application of Raman spectroscopy.

1. P.R. Ciriscioli and G.S. Springer, SAMPE J. 25 (3), 35 (1989)

2. W. Sichina and D. Shepard, Mater. Eng., 49 July 1989).

3. D.R. Day, D.D. Shepard, and A.S. Wall, "Thermoset Process Control Utilizing Microdielectric Sensors," Proc. ASME Conf. Adrumoed Composites and Processing Techlology (Chicago, [llinois), I (November 27-December 2, 1988)

4. S.S. Saliba, T.E. Saliba, and J.F. Lanzafame, "Acoustic Monitoring of Composite Materials During the Cure Cycle," Proc. 34th Int. SAMPE Symposium 34 (1), 397 (1989).

5. R.E. Schirmer and A.G. Gargus, Am. Laboratory 37, (November 1988).

6. P.R. Young, M.A. Druy, W.A. Stevenson, and D.A.C. Compton, SAMPE J. 25 (2), (1989).

7. M.A. Druy, L. Elandjian, W.A. Stevenson, R.D. Driver, G.M. Leskowitz, and L.E. Curtiss, "Fourier-Transform Infrared (FTIR) Fiber Optic Monitoring of Composites During Cure in an Autoclave," SPIE Proc. Vol. 1170, Fiber Optic Smart Structures and Skins II (Boston, Massachusetts), 150 (September 5-8, 1989). 
8. R.L. Levy and S.D. Schwab, Polymu. Commers. 12 (2), 96 (1991).

9. N.H. Sung, W. Dang, and H.J. Paik, "I" situ Monitoring of Epoxy Cure by Fiber-Optic Molecular Sensors," Proc. 36th lith. SAMPE Symurosinm 36 (2), $1461(1991)$.

10. H. Dannenberg, SPE Trims. 3 (1), 78 (1963).

11. D.L. Gerrard and W.F. Maddams, Appl. Spectrosic. Revi 22, 251 (1986).

12. W.F. Maddams, American Laborntory (March 1986).

13. C.E. Miller, D.D. Archibald, M.L. Myrick, and S.M. Angel, Appl. Spectrosc. 44, 1297 (1990)).

14. W. Doyle and N.A. Jennings, Spectroscopy Int. /. 5 (1), $34(1990)$ ).

15. C. Johnson and S.L. Wunder, SAMPE /. 26 (2), 19 (1990).

16. J.C. Johnson, FT-Raman Imostigation of Curing Reactions in Polyimicte's, Ph.D. Dissertation, Temple University, Philadelphia, Pennsylvania (1990).
17. S.M. Angel, M.L. Myrick, and T.M. Vess, "Remote Raman Spectroscopy Using Diode Lasels and Fiber-Optic Probes,"Proc. SPIE '91, Optical Methods for Llltans'msition Detection and Analysis: Tidmiques and Applications (Los Angeles, California), 1435, 72 (1991).

18. M.L. Myrick, S.M. Angel, R.E. Lyon, and T.M. Vess, SAMPE I. 28 (4), 37 (1992).

19. T.T. Chiao and R.L. Moore, "A Room-Temperature Curable Epoxy for Advanced Composites," Proc. 29th Anmual Teimical Conf. Reinfored Plnstics/Compusites lnst., SPI, Section 16-B, 1 (1974).

20. F.M. Kong, C.M. Walkup, and R.J. Morgan, "Structure-Property Relationships of PolyethertiamineCured Bisphenol-A-diglycidyl Ether Epoxies," Eproxy Resin Ch'mistry II, R.S. Bauer (Ed.), ACS Symposium Series 221, 211, 1983. 


\section{Modeling Superplastic Materials}

Donald R. Lesuer,
Chol K. Syn, and
Charles S. Preuss

Engineering Sciences

Mechanical Engineering

\author{
Peter J. Raboin \\ Nuclear Explosives Engineering \\ Mechunical Engineering
}

We have developed a model that accounts for grain growth during superplastic flow, and its subsequent influence on stress/strain/strain rate behavior. Our studies are experimentally based and have involved two different types of superplastic materials: a quasi-single phase metal, Coronze 638, and a microduplex metal, ultrahigh-carbon steel. We have studied the kinetics of strain-enhanced grain growth in both materials as a function of strain, strain rate, and temperature. An equation for the rate of grain growth has been developed that incorporates the influence of temperature. Our model integrates grain growth laws derived from these studies, with two mechanism-based, rate-dependent constitutive laws to predict the stress/strain/ strain rate behavior of materials during superplastic deformation. The material model has been added to the NIKE2D code through an enhancement of the Deformation Mechanism Model. The predictions of the model have been compared with data from several experiments.

\section{Introduction}

Superplasticity is the capability to deform crystalline solids in tension to unusually large plastic strains, often well in excess of $1000 \%$. This phenomenon results from the ability of the material to resist localized deformation much the same as hot glass. The material also deforms with very low flow stress. Thus, materials with superplastic properties provide the opportunity to form complex components into shapes very near final dimension. This greatly reduces machining and material costs and minimizes the amount of scrap produced.

Superplastic materials exhibit high elongations, because a deformation mechanism known as grain boundary sliding (GBS) is active. This deformation behavior occurs within a relatively narrow range of temperature and strain rate. If the strain rate is too high, then a different mechanism called diffusion-controlled dislocation creep (slip creep) is activated, and ductilities are substantially reduced. On the other hand, if the strain rate is too low, then a deformation mechanism known as diffusional flow prevails, and the ductility is also reduced relative to GBS. From a commercial standpoint, forming components at high strain rates is attractive, because operations can be done with less time and cost. Often this means superplastically forming at strain rates close to the slip creep regime. Thus, our work is concentrating on the two higher strain rate regimes, GBS and slip creep.

The active deformation mechanisms also depend strongly on the microstructure of the material, such as an ultra-fine grain structure. Unfortunately, these ultra-fine grains can grow during deformation, resulting in the loss of superplasticity. Thus, it is important to gain a quantitative understanding of this process and its influence on material forming.

For these reasons, material models for the constitutive behavior of materials during superplastic flow should account for microstructure, its evolution, and changes in deformation mechanism throughout the deformation history. The objective of this project is to develop a model of these structural changes and their influence on stress/strain/ strain rate behavior, using mechanism-based constitutive laws.

\section{Progress}

In our work during FY-91, we (a) established the kinetics of strain-enhanced grain growth for isothermal conditions and (b) developed a model that integrates these grain grow th laws with mech- 
(a)

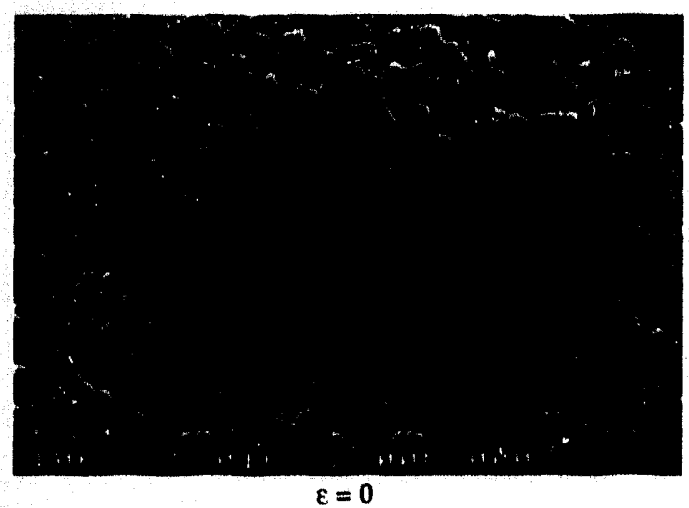

(c)

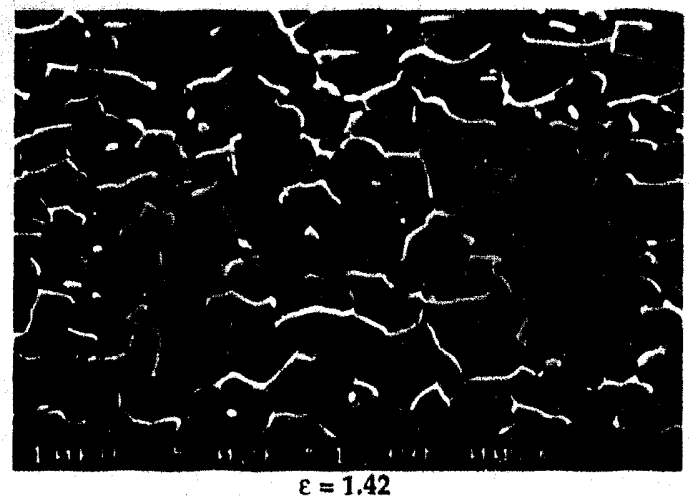

(b)

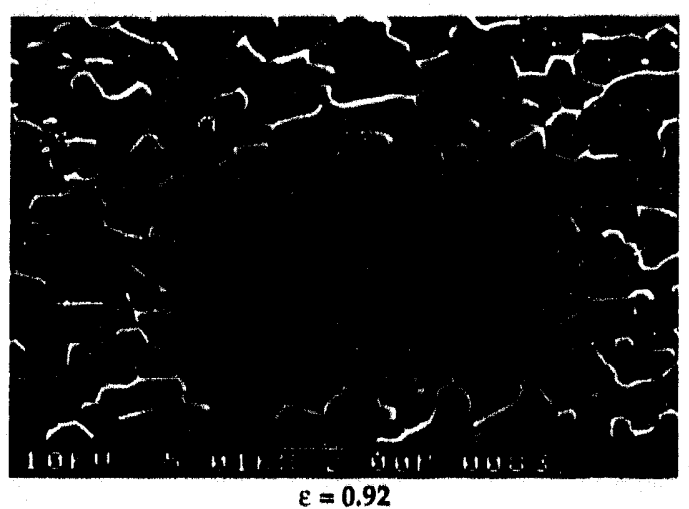

(d)

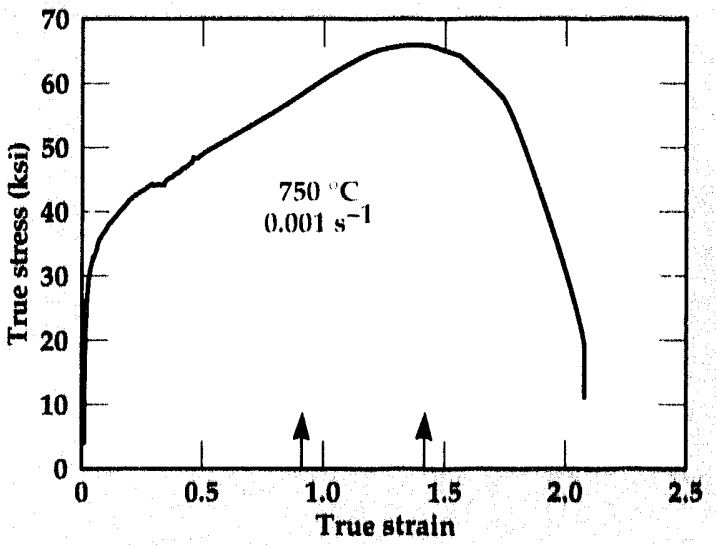

Fgure 1. Microstructure of ultrahigh-carbon steel before deformation (a) and after superplastic deformation to a true straln of .92 (b) and 1.42 (c), respectively. Microstructure cons/sts of ferrite grains and Iron carbide particles. Superplastic deformation has caused growth in both the ferrite grains and the carbide particles. The true stress/true straln behavior for this material is shown in (d). Strains at which the photomicrographs were taken are indicated on the plot.

anism-based constitutive equations. During FY92, we expanded the strain-enhanced graingrowth equations to account for the influence of temperature. The material model was also put into the NIKE2D code, and the performanoe of the model was evaluated with laboratory experiments.

\section{Microstructural Evolution}

Our studies have involved two superplastic materials with significantly different microstructures: ultrahigh-carbon sted (UHCS), which has a microduplex structure, and (oromze 63.38 , which is yuasi-single phase. In both of these materials, the dominant microstructural change during superplastic deformation is grain growth, and no dynamic recrystallization was expected at the temperaturesand strain rates of interest. The UHCS had the composition l' $-1.8 C^{\circ}-1.6 \wedge 1-1.5 \mathrm{Cr}-.5 \mathrm{Mn}$ and had been thermomechanically processed to prodece a matrix of ultrafine, equiaxed ferrite grains (mean lincar interept wasapproximately $(0.7+\mu \mathrm{m})$ containing spheroidized carbides. The Coronze 6.38 (C (1-2.8A1-1.8Si-().4C(0) is a commercially available alloy that consists of essentially pure copper containing a sub-micron-size dispersion of Cosi and CoSiz particles. The material was received as a reperitedly rolled and annealed sheet with mean linear intercept grain size eyual to 1.9 microns. Further details of the experimental plan are reportedelsewhere.

Strain-Enhanced Grain Growth. Figure 1 shows the influence of superplastic deformation at 750 ( $\mathrm{C}$, and a true strain rate of (0)1/son the microstructure of UHCS. Figure 1a was taken in the grip section of the sample, and was thes expesed to the testing temperature witheut plastic deformation. Figures $1 b$ and $1 c$ were taken in the galge section of samples deformed to true strains of 0.92 and 1.42 , respectively. A comparisen of the figures show's strain-enhanced grain growth in that the ferrite grains have grown. The carbide particleshave also coarsened, and the size of the ferrite grains appears to be determined by the intercarbide spale- 


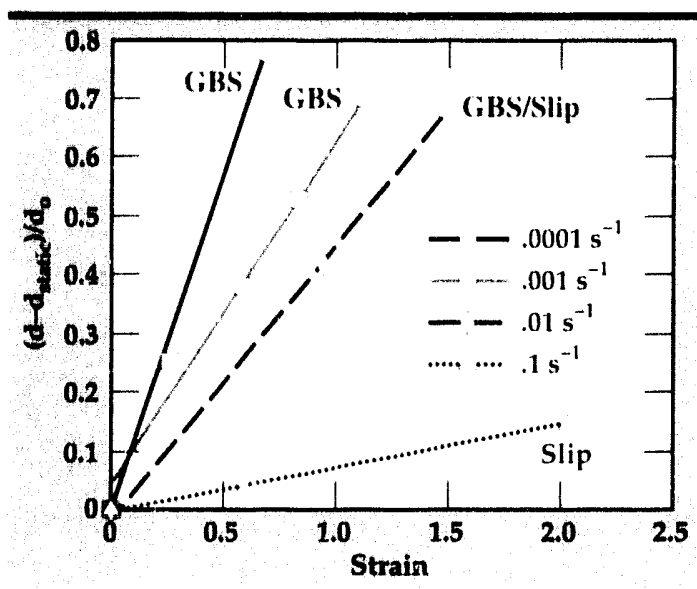

Figure 2. Normalized strainenhanced grain growth vs strain for Comonze superplastically deformed at four true strain rates. Dominant deformation mechanism is noted for each strain rate.

ing. This suggests that the kinetics of grain growth are determined by the kinetics of carbide coarsening. The stress/strain curve in Fig. 1d shows the importance of this grain growth on the deformation behavior of UHCS: increasing the grain size from its initial size $(0.74 \mu \mathrm{m})$ to the size at a strain of $1.42(1.48 \mu \mathrm{m})$ has raised the flow stress from $5 \mathrm{ksi}$ to over $9 \mathrm{ksi}$. Thus, grain growth has produced significant hardening, and the grain size is an important parameter for characterizing the current mechanical state of the material.

In these studies, static annealing grain growth (normal grain growth) and strain-enhanced grain growth are assumed to be additive. Thus, the kinetics of grain grow'th can be expressed as

$$
\frac{\dot{d}}{d_{0}}=\frac{\dot{d}_{d}}{d_{0}}+\frac{\dot{d}_{(1}}{d_{0}}
$$

where $d$ is the total ate of grain growth; $\dot{d}_{d}$ is the grain grow th rate due to static annealing; $d_{x}$ is the grain grow th rate due to strain; and $\dot{d}_{1}$ is the initial grain size prior to deformation or exposure to elevated temperature.

The grain structure in the gage section of samples is the result of both static and strain-enhanced grain growth. On the other hand, the grain structure in the grip is the result of static grain growth only. The strain-enhanced grain grow th was calculated as the difference in mean-linear-intercept grain size between medsurements taken in the gage and grip sections of the sample. We used this procedure to determine the normalized strain-enhanced grain grow th response for Coronze. Wilkinson and Caceres- have obtained data for this
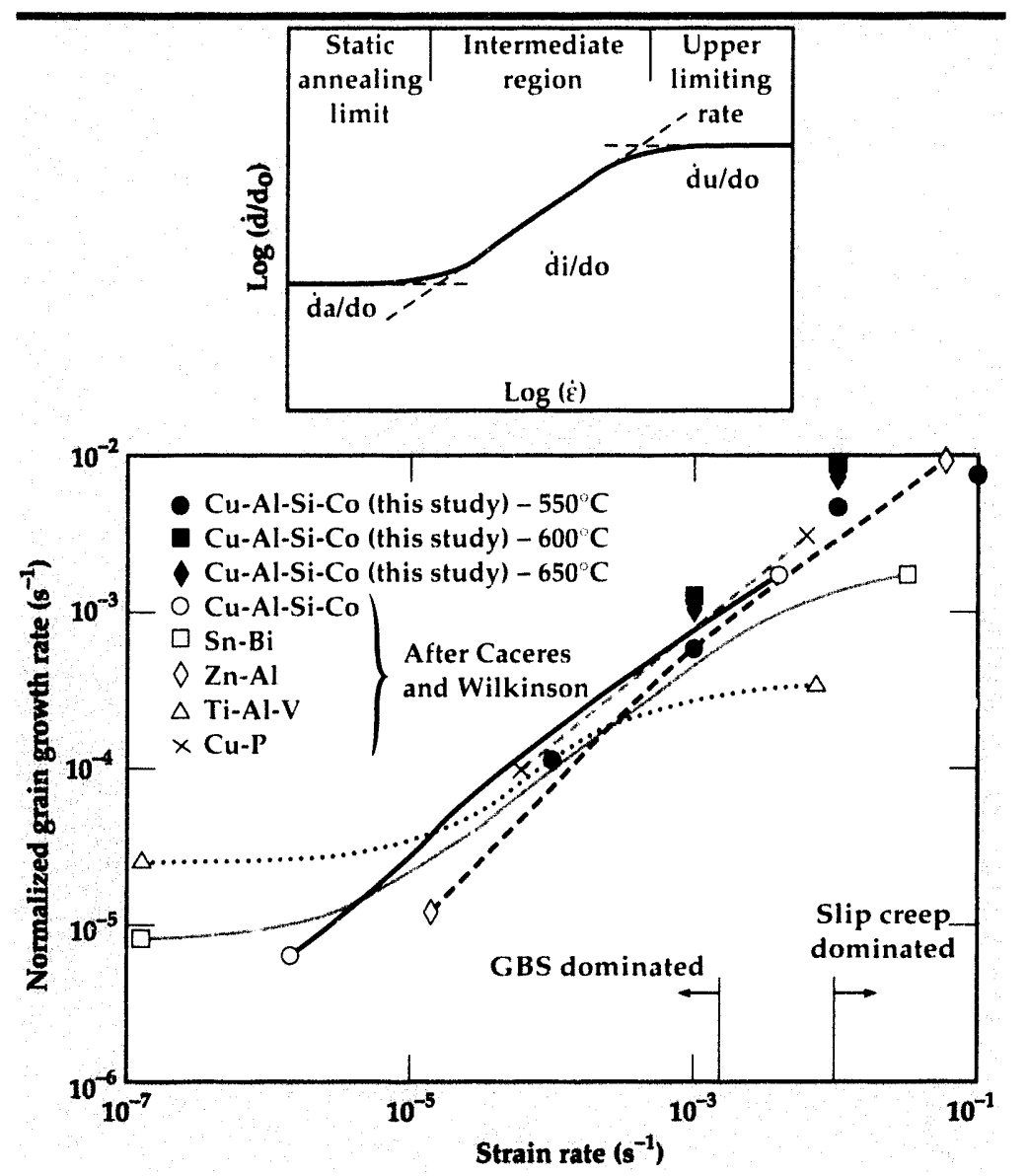

Figure 3. Normalized grain growth rate vs strain rate for a number of quasi-single phase and microduplex superplastic materiais. Plot is from the work of Caceres and Wilkinson. ${ }^{2}$ Data from our study of Coronze at $550 \mathrm{C}, 600 \mathrm{C}$, and $650 \mathrm{C}$ have been added to the plot. The strain rates over which there is a transition in deformation mechanism from GBS to slip creep, are indicated. The inset shows the three different regions for the curve.

material. The present studies have obtained data at higher strain rates. The strain-enhanced grain grow th for Coronze is plotted as a function of true strain in Fig. 2, for tests conducted at $550^{\circ} \mathrm{C}$ and four strain rates. Results have been normalized by the initial grain size. The tests at the three slowest strain rates were in the region in which CBS is the dominant deformation mechanism. The test at the highest strain rate was in the region where the dominant deformation mechanism was slip creep. For the three slowest strain rates, the normalized strain-enhanced grain grow th was found to have a linear dependence on strain and a power-law dependence on strain rate. These results are consistent with the observations of Caceres and Wilkinson on the Coronze alloy.2 For the highest strain rate, the grain growth data in Fig. 2 had a much smaller slope. The reason for this will be discussed in the following paragraphs. 


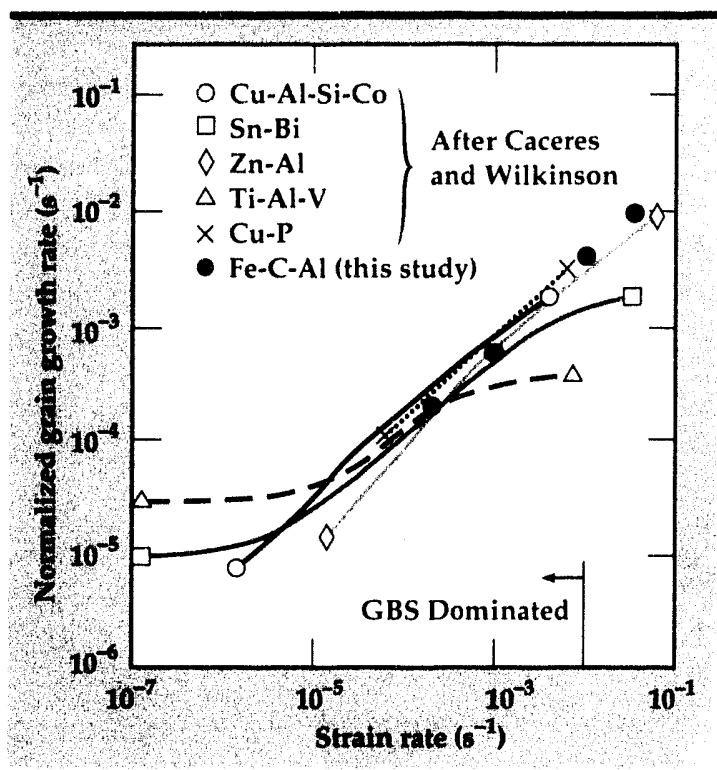

Figure 4. Normalized grain growth rate vs strain rate for a number of quasi-single phase and microduplex supeplastic materials. Plot is from the work of Caceres and Wilkinson.2 Data from our study of the superplastic deformation of UHCS at $750^{\circ} \mathrm{C}$ has been added to the plot. Strain rate below which GBS is the primary deformation mechanism, is indicated.

The normalized, strain-enhanced grain growth rate (with respect to time) can be calculated from the data in Fig. 2, by multiplying the slopes of individual lines by the strain rate for that test. These grain growth rates have been calculated and added to a figure previously reported by Wilkinson and Caceres, ${ }^{2}$ which shows a log-log plot of normalized grain growth rate vs strain rate. The results are shown in Fig. 3. The plot is quite significant, since it shows data for both quasi-single phase and microduplex materials, for different homologous temperatures and for a range of starting grain sizes. It is clear that a common equation can describe the grain growth behavior of a number of different materials, including Coronze. The curve has three distinct regions. In one region, the nor-

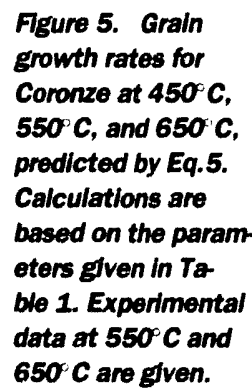

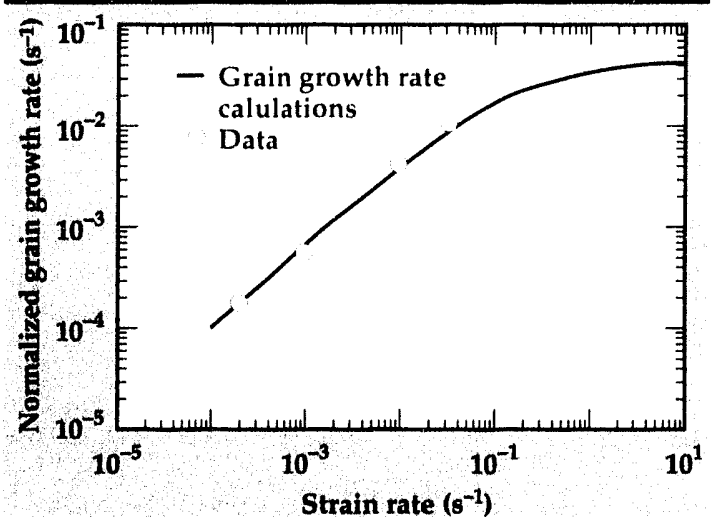

Figure 6. Grain growth rates for UHCS at $750 \mathrm{C}$, predicted by Eq. 5. Calculations are based on the parameters in Ta ble 1. Experimental data is provided.

malized grain growth rate is a power law function of strain rate; at higher or lower strain rates, the normalized grain growth rate reaches a limiting value that is independent of strain rate. These regions are shown schematically in the inset for Fig. 3. The region at the lowest strain rate is the result of static grain growth, whereas the regions at the intermediate and high strain rates represent the result of strain-enhanced grain growth. It is reasonable to assume that the highest grain growth rate represents a limiting rate determined by the kinetics of grain boundary migration. The curve shown in Fig. 3 can be described by

$$
\frac{\dot{d}}{d_{0}}=\frac{\dot{d}_{u}}{d_{0}}+\frac{1}{d_{0}}\left(\frac{\dot{d}_{i} \dot{d}_{u}}{\dot{d}_{i}+\dot{d}_{u}}\right),
$$

where $\dot{d}_{j}$ is the grain growth rate at intermediate strain rates, and $\dot{d}_{u}$ is the upper limiting grain growth rate. The intermediate region has a powerlaw dependence on strain rate, which produces

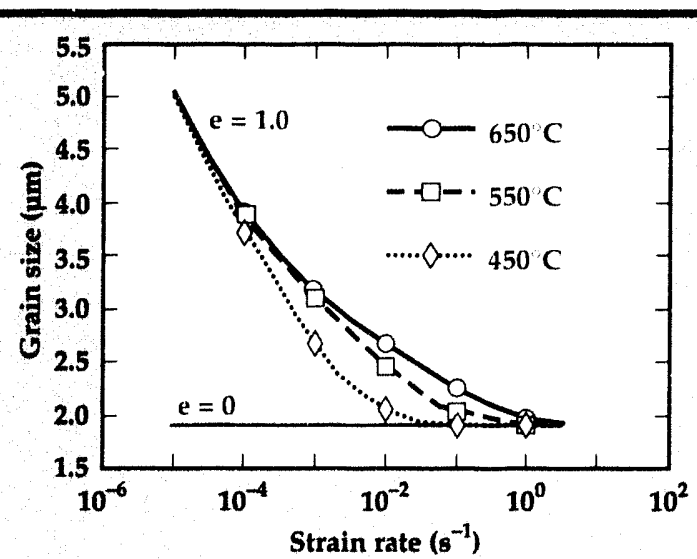

Figure 7. Calculated grain sizes for Coronze after constant strain rate testing to a true strain of 1 at the indicated strain rates. 
the following empirical expression for the normalized rate of grain growth:

$$
\frac{\dot{d}}{d_{0}}=\frac{\dot{d}_{n}}{d_{0}}+\frac{1}{d_{0}}\left(\frac{\lambda_{0} \dot{\varepsilon}^{n} \dot{d}_{u}}{\lambda_{0} \dot{\varepsilon}^{\prime \prime}+\dot{d}_{u}}\right),
$$

where $\lambda_{1}$ and $n$ are constants.

The strain rates at which there is a shift in the operating deformation mechanisms (from GBS to slip creep) are also shown in Fig. 3. It is important to note that the grain growth rates for the three slowest strain rates appear to have a power-law dependence on strain rate. The grain growth rate for the highest strain rate, however, shows a substantially smaller increase with increasing strain rate than the grain growth rates at the lower strain rates. This transition occurs at about the same strain rate as the transition to slip-creep-dominated deformation. The obvious implication is that the loss of GBS as a deformation mechanism has reduced the contributions of strain-enhanced grain growth to the total grain growth rate. Several mechanisms have been proposed to explain strain-enhanced grain growth. ${ }^{\text {th }}$ All of these mechanisms result from grain boundary sliding or grain switching events. It is reasonable to assume that strainenhanced grain growth will exist only if these mechanisms provide significant contributions to the total strain. Thus, contributions from strainenhanced grain growth can be limited by a loss of superplastic flow or by the limiting grain growth rates defined by the rates of grain boundary migration.

Identical procedures were used to determine the normalized strain-enhanced grain growth rate for UHCS during superplastic deformation at $750^{\circ} \mathrm{C}$. Results are presented in Fig. 4 and fall within the range of grain growth rates for other materials represented on the plot. For UHCS, no upper limit is reached on grain growth rate over the strain rates studied.

Temperature Dependence of Strain-Enhanced Grain Growth. A general extension of Eq. 3 that accounts for the temperature dependence of grain growth can be developed assuming different temperature dependencies for the three processes in Eq. 2. The temperature dependence of normal grain growth kinetics has been studied and equations developed (see, for example, Ref. 7). The primary interest in this study is strain-enhanced grain growth, and thus the intermediate and upper rate

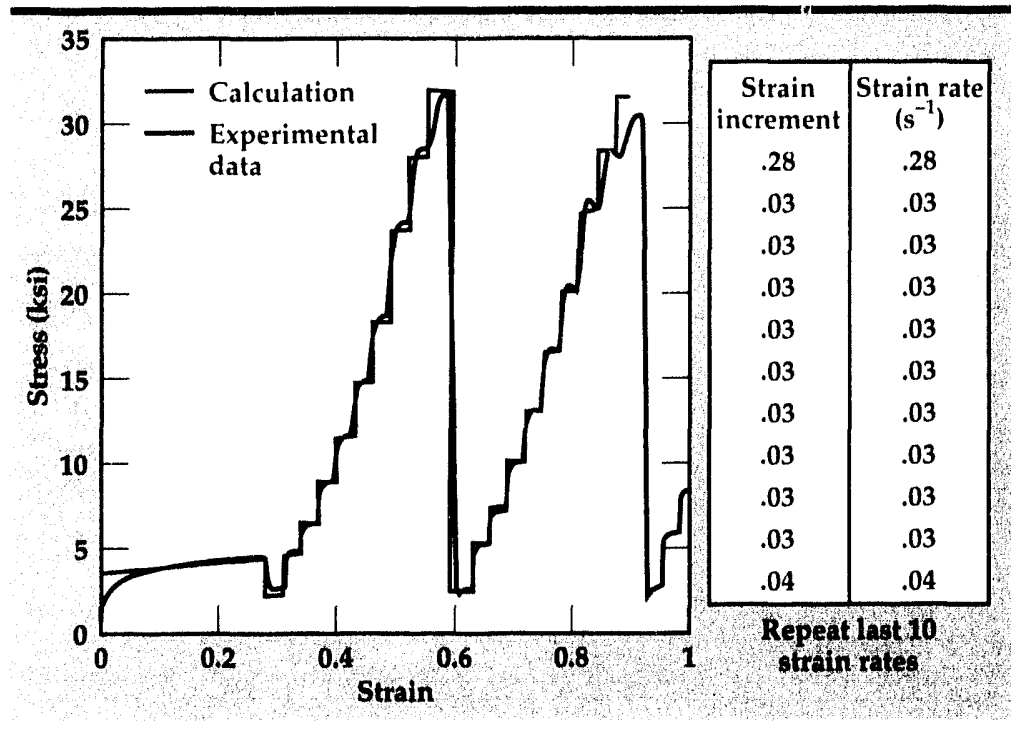

processes represented in Eq. 2 . The temperature dependence of these processes can be represented as

$$
\begin{aligned}
& \dot{d}_{i}=\lambda_{0} \dot{\varepsilon}^{n} \exp \left(\frac{-Q_{i}}{R T}\right) \\
& \dot{d}_{u}=\left(\dot{d}_{u}\right)_{0} \exp \left(\frac{-Q_{u}}{R T}\right),
\end{aligned}
$$

where $Q_{i}$ and $Q_{u}$ are activation energies for the intermediate and upper regions, respectively; $\lambda_{1}$ and $\left(\dot{d}_{1}\right)_{1}$ are constants; $R$ is the gas constant, and T is the absolute temperature. Combining these expressions yields a general equation for the temperature dependence of strain-enhanced grain growth:

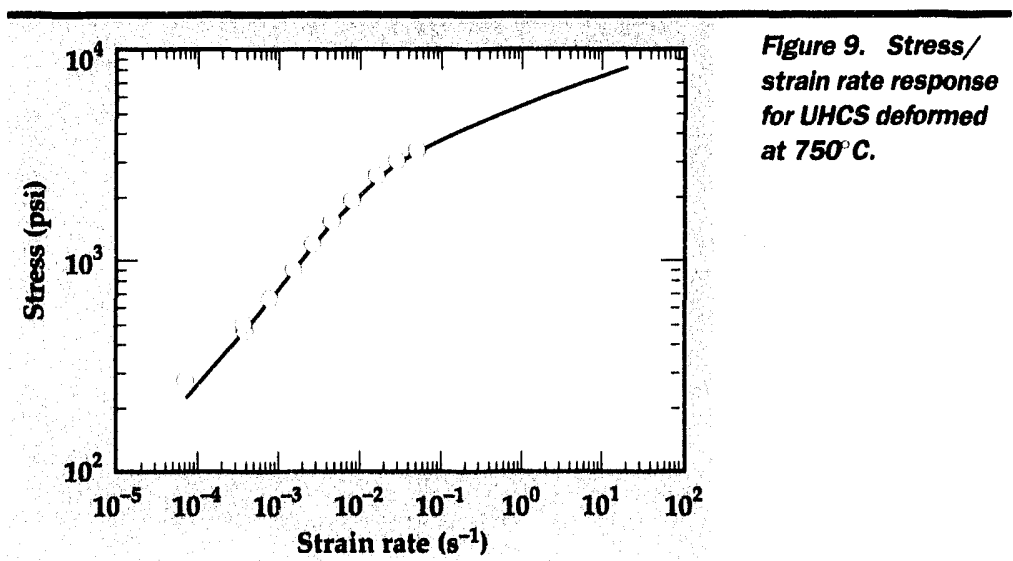

Figure 8. Stress/ straln response for UHCS deformed at $750^{\circ} \mathrm{C}$ through a predetermined strain rate/strain history. The straln rate/ strain history /s shown in the inset. The calculations are based on the material model described in this report. for UHCS deformed at $750^{\circ} \mathrm{C}$. 
Fringes of effective

plastic strain

\section{UHCS at $1023 \mathrm{~K}$, \\ High strain rate \\ time $=1.00000^{-02}$ \\ $\mathrm{dsf}=1.00000^{+00}$}

(a)

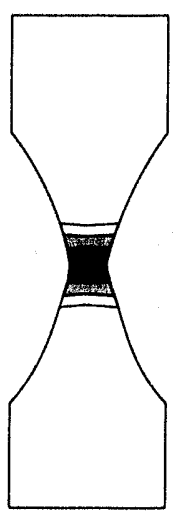

UHCS at $1023 \mathrm{~K}$,

High strain rate time $=1.00000^{-02}$ $\mathrm{dsf}=1.00000^{+00}$ (c)

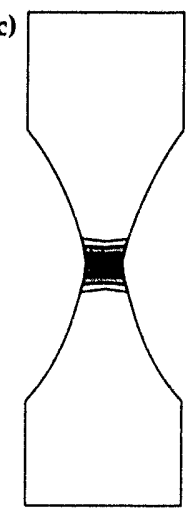

Minval $=7.40^{-07}$ Maxval $=8.67^{-07}$ fringe levels

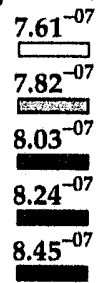

Minval $=5.15^{-04}$

Maxval $=1.02^{+02}$ fringe levels

$$
1.69^{+01}
$$$$
3.39^{+01}
$$$$
5.00^{+01}
$$$$
\text { - } 6.77^{+01}
$$$$
\text { , } 8.77^{+01}
$$$$
8.46^{+01}
$$

UHCS at $1023 \mathrm{~K}$, Low strain rate $=0.01$ time $=1.00000^{+01}$ $\mathrm{dsf}=1.00000^{+00}$ (b)

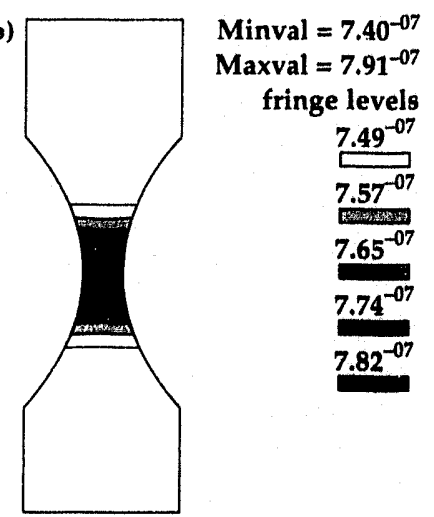

UHCS at $1023 \mathrm{~K}$, Low strain rate $=0.01$ $\mathrm{dsf}=1.00000^{+00}$

(d) time $=1.00000^{+01}$

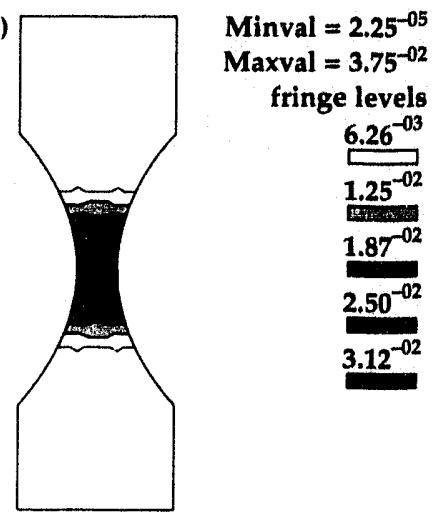

Figure 10. Hourglass-shaped sample of UHCS deformed at $750 \mathrm{C}$ for two different extension rates: one in which GBS is the dominant deformation mechanism, and one in which slip creep is the dominant deformation mechanism. The figure shows contours of constant grain size and strain rate for the sample.

Table 1. Parameters used in Eq. 5 for temperature dependence of strainenhanced grain growth.

\begin{tabular}{|c|c|c|c|c|c|c|}
\hline & $\begin{array}{c}d_{0} \\
(\mu \mathrm{m})\end{array}$ & $\begin{array}{c}\lambda_{0} \\
{\left[(\mu \mathrm{m} / \mathrm{s}) \mathbf{s}^{n}\right]}\end{array}$ & $\begin{array}{c}\left(\dot{d}_{u}\right)_{0} \\
(\mu \mathrm{m} / \mathrm{s})\end{array}$ & $\mathrm{n}$ & $\mathbf{Q}_{\mathbf{i}}$ & $\begin{array}{c}\mathbf{Q}_{\mathrm{u}} \\
(\mathrm{kJ} / \mathrm{mole})\end{array}$ \\
\hline Cirrumse & 1.9 & .178 & $7.98 \times 10^{4}$ & .816 & () & $1114^{4}$ \\
\hline Uhrs & .74 & .176 & $1.42 \times 107$ & .790 & () & 17()$^{\dagger}$ \\
\hline
\end{tabular}

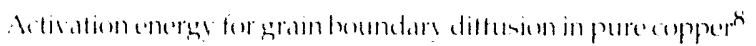

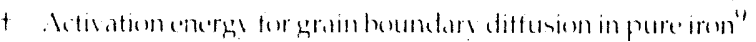

$$
\frac{\dot{d}_{\mathrm{Si}}}{d_{0}}=\frac{1}{d_{0}}\left\{\frac{\lambda_{11} \dot{\varepsilon}^{\prime \prime}\left(\dot{d}_{11}\right)_{0} \exp \left[\begin{array}{c}
-\left(Q_{i}+Q_{11}\right) \\
R T
\end{array}\right]}{\lambda_{0} \dot{\varepsilon}^{\prime \prime} \exp \left(\begin{array}{c}
-Q_{i} \\
R T
\end{array}\right)+\left(\dot{d}_{11}\right)_{0} \exp \left(\begin{array}{c}
-Q_{11} \\
R T
\end{array}\right)}\right\}
$$

The temperature dependence of strain-enhanced grain growth for the Coronze alloy was experimentally evaluated at $6000^{\circ} \mathrm{C}$ and $650^{\circ} \mathrm{C}$. The resulting grain growth rates have been added to the plot in Fig. 3, and appear to fall within the range of strain-enhanced grain growth rates for other materials. These results suggest that strainenhanced grain growth for the Coronze alloy is independent of temperature and that $Q_{i}$ for this material is zero. As mentioned in the previous section, the limiting grain growth rate at high strain rate is probably controlled by the rate of grain boundary migration. We therefore assume that a reasonable value for $Q_{u}$ is the activation energy for grain boundary diffusion. The calculated grain grow th rates that are predicted by Eq. 5 are plotted as a function of strain rate in Fig. 5. Calculations are shown for three temperatures, $450{ }^{\circ} \mathrm{C}, 550^{\circ} \mathrm{C}$, and $650^{\circ} \mathrm{C}$; the parameters are given in Table 1. The calculated grain growth rates show good agreement with rates derived from experimental data. Because the strain-enhanced grain growth is independent of temperature in the intermediate region, at very high temperatures (higher than the temperature studied here), the contribution of static annealing to the total grain growth rate could be significantly higher than the contribution from strain-enhanced grain growth. In Table 1, the parameters for UHCS are also given. Both Coronze and UHCShave very similar strain rate exponents (n) and values for the constant $\lambda$. The calculated strain-enhanced grain growth rates for UHCS deformed at $750^{\circ} \mathrm{C}$ are shown in Fig. 6. Good agreement was obtained with experimental data.

The final grain sizes that would be obtained for Coronze after tensile testing (to a true strain equal to 1) at a constant strain rate are shown in Fig. 7. Calculations, which were done for three temperatures $\left(450^{\circ} \mathrm{C}, 550^{\circ} \mathrm{C}\right.$, and $\left.650^{\circ} \mathrm{C}\right)$, are based on Eq. 5, using the parameters given in Table 1, and, thus, do not include the effects of static annealing. Results in Fig. 7 show a decreasing final grain size with increasing strain rate and very little grain growth above .1/s for all testing temperatures. Cirain growth decreases with increasing strain rate (Fig. 7) despite the increasing grain growth rate 
with increasing strain rate (Fig. 5). This occurs because the strain rate exponent (n) in Eq. 5 is less than one. The total amount of grain growth is very sensitive to the value of $n$.

\section{Mechanical Response}

Two rate-dependent constitutive equations have been used for GBS and slip creep,

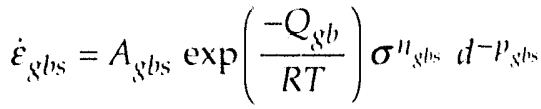

$$
\begin{aligned}
& \dot{\varepsilon}_{\text {slip }}=A_{\text {slip }} \exp \left(\frac{-Q_{1}}{R T}\right) \sigma^{\prime \prime l i p} \lambda^{\prime} \text { slip, }
\end{aligned}
$$

where $\dot{\varepsilon}_{\text {ghs }}$ and $\dot{\varepsilon}_{\text {slip }}$ are the strain rates for grain boundary sliding an ${ }^{\mathrm{TM}} d$ slip creep, respectively; $\sigma$

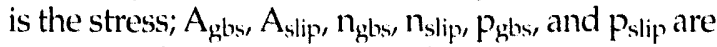
constants; $\lambda$ is the minimum barrier spacing governing slip creep (typically, the interparticle spacing or the grain size); $d$ is the grain size; $Q_{g b}$ is the activation energy for grain boundary diffusion; and $Q_{1}$ is the activation energy for lattice diffusion. Since the deformation mechanisms represented by these equations are additive, the total strain rate can be represented by

$$
\dot{\varepsilon}_{\text {lotal }}=\dot{\varepsilon}_{\text {slip }}+\varepsilon_{\text {glss }} .
$$

The mean, linear, intercept grain size is typically used for the grain size term in Eqs. 6 and 7. For fine grain materials deforming in or near the region of GBS, the minimum barrier spacing is the grain size, and thus for these studies, we have assumed that $\lambda$ equals $d$. The grain size was obtained from a time integration of Eq. 1.

\section{Model Implementation and Evaluation}

The grain growth kinetics, expressed by Eqs. 1 and 5 , and the constitutive laws, expressed by Eqs. 6, 7, and 8, were integrated into an existing material model in the NIKE2D code, called the Deformation Mechanism Model (DMM)."1' This material model solves the constitutive equations, with an implicit solution procedure. The evolution of grain size is also solved with an implicit procedure. The numerical methods used in this model emphasize accuracy, but all of the algorithms are vectorized for the Cray computer. Generally, the

\begin{tabular}{|c|c|c|c|}
\hline$A_{\text {gbs }}$ & $\mathbf{Q}_{\mathrm{gb}}{ }^{*}$ & $\mathrm{n}_{\mathrm{gbs}}$ & $\mathbf{p}_{\mathbf{g b s}}$ \\
\hline$\left|\mathrm{s}^{-1}(\mathrm{psi})^{-11}(\mu \mathrm{m}) \mathrm{P}\right|$ & (kJ/mole) & & \\
\hline $1.84 \times 10^{-3}$ & 177 & 2.27 & 3.0 \\
\hline$A_{\text {slip }}$ & $\mathbf{Q}_{1}^{\dagger}$ & $n_{\text {slip }}$ & Polip \\
\hline$\left[\mathrm{s}^{-1}(\mathrm{psi})^{-11}(\mu \mathrm{m})^{-\mathrm{p}}\right]$ & (kJ/mole) & & \\
\hline $1.41 \times 10^{-21}$ & 252 & 7.14 & 3.0 \\
\hline
\end{tabular}

Table 2 Parameters used in Eqs. 6 and 7 for UHCS.

* determined experimentally

+ obtained from Ref. 9

speed performance of the DMM is within a factor of three of NIKE2D model 19, a rate-dependent, power-law plasticity model.

We have evaluated the performance of the material model, using a series of experiments of increasing complexity. The first experiments were simple tensile tests conducted at constant true strain rates, and excellent agreement was obtained between model predictions and experimental data. The results were reported in our FY-9111 report. The second set of experiments involved deforming tensile samples through a predetermined strain rate/strain history. This applied strain/strain rate history and the resulting stress/strain response for UHCS deformed at $750^{\circ} \mathrm{C}$ is shown in Fig. 8. The parameters used in Eqs. 6 and 7 are shown in Table 2. In Fig. 9, we show the stress/strain rate behavior of UHCS. In both cases, excellent agreement was obtained between model predictions and experimental data. A third set of calculations was done to evaluate the material model on a sample containing a non-uniform stress state. The sample had an hourglass shape and was deformed at two different constant extension rates. At one rate, GBS was the dominant deformation mechanism, and at the other rate, slip creep was the dominant deformation mechanism. The extension rates are indicated in Fig. 10, which shows contours of constant grain size (Figs. 10a and 10b) and constant strain rate (Figs. 10c and 10d) after an extension of $x$ in. The simple deformed in the slip creep region has started to neck, and the contours of strain rate are highly localized. The sample deformed in the region of GBS has avoided necking (exhibited characteristics leading to superplastic behavior) by distributing the strain rates throughout the hourglass region. 


\section{Conclusions}

We draw four conclusions from our work:

1. The dependence of grain growth rate on strain rate for superplastic UHCS and coronze falls on a master curve, as originally proposed by Wilkinson and Caceres. ${ }^{2}$ In the copper alloy, the transition in grain growth rate from a power-law dependence on strain rate to an upper limiting rate occurs at the transition from GBS-dominated behavior to slip-creep-dominated behavior. The transition to an upper limiting rate ( $\dot{d}_{u}$ in Fig. 3) can occur because of a loss of superplastic flow or a limiting grain growth rate defined by grain boundary migration. For UHCS, within the strain rates studied, no upper limit was found to the grain growth rate.

2. An equation describing the temperature dependence of the strain-enhanced grain growth rate has been developed. The equation predicts grain growth rates that agree well with experimental data. For Coronze, strain-enhanced grain growth appears to be independent of temperature in the intermediate region. In the high strain rate region, the strain-enhanced grain growth rate appears to have an activation energy equal to the activation energy for grain boundary diffusion.

3. A material model has been developed that combines the temperature-dependent grain growth law described above and mechanism-based constitutive equations.

4. This model was incorporated into the NIKE2D code, and validation experiments show excellent agreement between model calculations and experimental data.

\section{Acknowledgements}

We are indebted to Oleg Sherby (Stanford University) and Amiya Mukherjee (University of California Davis) for helpful discussions on superplasticity. We are also indebted to Jack Crane (Olin Corporation) for providing the Coronze 638 and to Oleg Sherby for providing the superplastic ultrahigh-carbon steel.

1. D.R. Lesuer, C.K. Syn, K.L.Cadwell, and S.C. Mance, "Microstructural Change and Its Influence on StressStrain Behavior of Superplastic Materials," Superplasticity in Advanced Mnterials, S. Hori, M. Tokizane, and N. Furushiro (Eds.), (Osaka, Japan), 139, 1991.

2. D.S. Wilkinson and C.H. Caceres, J. Mater. Sci. Lett. 3, 395 (1984).

3. M.A. Clark and T.H. Alden, Actu Mctall. 21, 1195 (1973).

4. D.S. Wilkinson and C.H. Caceres, Actn Mctall. 32 (9), 1335 (1984).

5. K. Holm, J.D. Embury, and G.R. Purdy, Actn Metall. 25, 1191 (1977).

6. D.J. Sherwood and C.H. Hamilton, Scriptn Metall. 25, 2873 (1991).

7. P. Cotterill and P.R. Mould, Recrystallizantionnand Grain Growth in Metals, John Wiley and Sons (New York, New York), 279, 1976.

8. M.F. Ashby, Actu Mitall. 20,887 (1972).

9. B. Walser and O.D. Sherby, Met. Trims. A 10A, 1461 (1979).

10. P. Raboin, A Deformation-Mechanism Material Motel for NIKE2D, Lawrence Livermore National Laboratory, Livermore, California, UCRL-ID-i12916(1993).

11. D.R. Lesuer, D.K. Syn, K.L.Cadwell, and C.S. Preuss, "Modeling Superplastic Materials," Engineering Re-

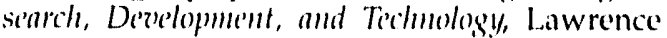
Livermore National Laboratoryl ivermore, California, UCRL_-53868-91 (1992). 

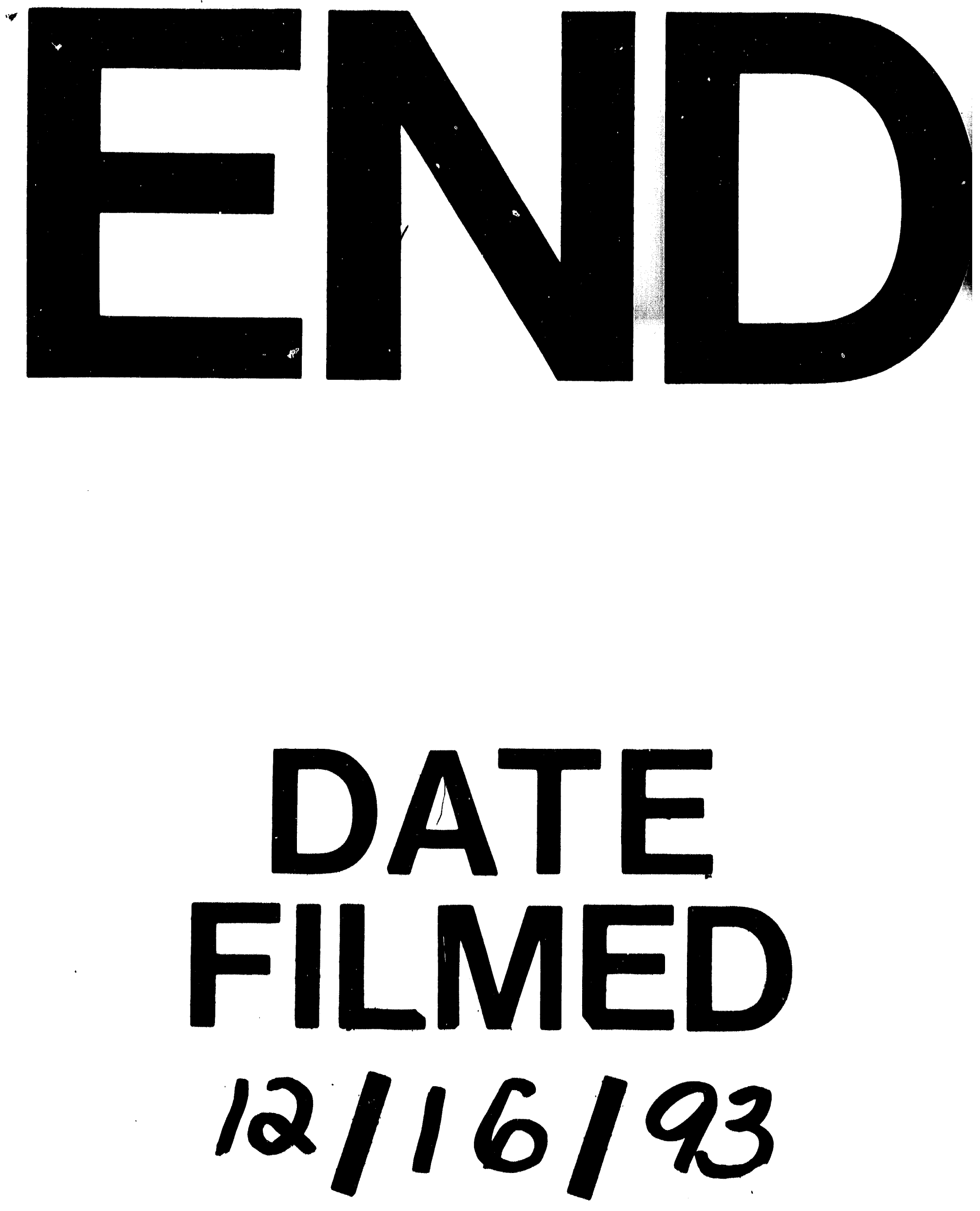
